\title{
Structure of the Q $\beta$ replicase, an RNA-dependent RNA polymerase consisting of viral and host proteins
}

\author{
Rune T. Kidmose ${ }^{a, b, 1}$, Nikita N. Vasiliev ${ }^{c, 1}$, Alexander B. Chetverinc, Gregers Rom Andersen ${ }^{a, b, 2}$, and Charlotte R. Knudsen ${ }^{a}$
}

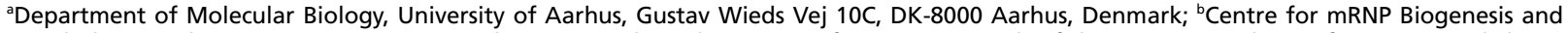
Metabolism, Aarhus University, DK-8000 Aarhus, Denmark; and Institute of Protein Research of the Russian Academy of Sciences, Pushchino, Moscow Region, 142290 Russia

Edited by Seth A. Darst, The Rockefeller University, New York, NY, and approved May 6, 2010 (received for review March 8, 2010)

The RNA-dependent RNA polymerase core complex formed upon infection of Escherichia coli by the bacteriophage $\mathrm{Q} \beta$ is composed of the viral catalytic $\beta$-subunit as well as the host translation elongation factors EF-Tu and EF-Ts, which are required for initiation of RNA replication. We have determined the crystal structure of the complex between the $\beta$-subunit and the two host proteins to $2.5-\AA$ resolution. Whereas the basic catalytic machinery in the viral subunit appears similar to other RNA-dependent RNA polymerases, a unique $\mathrm{C}$-terminal region of the $\beta$-subunit engages in extensive interactions with EF-Tu and may contribute to the separation of the transient duplex formed between the template and the nascent product to allow exponential amplification of the phage genome. The evolution of resistance by the host appears to be impaired because of the interactions of the $\beta$-subunit with parts of EF-Tu essential in recognition of aminoacyl-tRNA.

protein biosynthesis | virus

$\mathbf{M}$ any RNA viruses encode an RNA-dependent RNA polymerase ( $\mathrm{RdRp}$ ) responsible for the replication of their genome. Because the viral genomes are limited in size, host-encoded proteins play important roles during most steps of viral infection (1). Often, the virally encoded RdRp interacts with host-encoded proteins during infection to form a complex, which ensures template specificity and polymerase activity.

Several viral RdRps recruit host proteins with a canonical role in protein biosynthesis. A classical example is the $\mathrm{Q} \beta$ replicase complex consisting of the catalytic subunit encoded by the virus, the $\beta$-subunit, which hijacks the host translation elongation factors EF-Tu and EF-Ts as well as ribosomal protein S1 to form the $\mathrm{Q} \beta$ replicase holoenzyme. Once assembled, the holoenzyme is capable of replicating the plus-stranded genome and generating the complementary minus strand. An additional host protein, $\mathrm{Hfq}$, is required for efficient replication in vivo and in vitro (2). Contrary to the $\mathrm{Q} \beta$ plus strand, the minus strand, as well as certain synthetic polyribonucleotides and small replicating RNAs (RQ RNAs) (3) are productive templates in the absence of Hfq and even with a $\mathrm{Q} \beta$ replicase core complex lacking the $\mathrm{S} 1$ protein (4). The $\mathrm{Q} \beta$ replicase amplifies the $\mathrm{Q} \beta$ genome $10^{4}$-fold in less than 1 hour during infection (5). Whereas the $\mathrm{Q} \beta$ replicase exhibits extraordinary specificity toward its templates that prevents it from replicating host RNA, the template recognition elements remain poorly defined. Yet both the $\mathrm{Q} \beta$ plus and minus strands contain the motif $5^{\prime} \ldots \mathrm{CCCA}_{\mathrm{OH}^{-}} 3^{\prime}$, which is recognized by the replicase during initiation of replication (6).

In an uninfected bacterium, EF-Tu mediates the binding of amino-acylated tRNA (aa-tRNA) to the ribosomal A site via formation of a ternary complex, EF-Tu:GTP:aa-tRNA, and is released from the ribosome upon GTP hydrolysis in the form of EF-Tu:GDP. Subsequently, EF-Ts catalyzes the exchange of GDP for GTP on EF-Tu. In the Q $\beta$ replicase, the EF-Tu:EF-Ts subcomplex is necessary for initiation of replication of both the minus and plus strands (7) with EF-Tu being involved in template binding and recognition (8). EF-Ts may stabilize EF-Tu in a conformation with affinity for Q $\beta$ RNA templates in- stead of aa-tRNAs (9). Ribosomal protein S1 mediates recognition of the $\mathrm{Q} \beta$ plus strand (8), whereas the RNA chaperone Hfq is believed to mediate the access of the $\beta$-subunit to the $3^{\prime}$ end of the plus strand (10).

The eukaryotic counterpart of EF-Tu, eEF1A, is present in RdRp complexes formed upon infection with bovine viral diarrhea virus (11), polio virus (12), and tobacco mosaic virus (13). Structures of a variety of RdRps have been determined in the apo state or in complex with nucleotides and/or RNA and thereby provided insight into the molecular mechanisms of initiation and elongation (14). However, no structures of RdRp complexes consisting of virus- and host-encoded proteins have been described. Here we report the structure of the $Q \beta$ replicase core complex consisting of the viral $\beta$-subunit in complex with elongation factors EF-Tu and EF-Ts. The structure reveals how the virus elegantly takes advantage of the normal function of EF-Tu in translation to replicate its own genome.

\section{Results}

Functional Relevance of the Crystallized Protein. For crystallization, we used a fusion protein (consisting of EF-Ts, EF-Tu, and $\mathrm{His}_{6}$-tagged $\beta$-subunit), whose activity is similar to that of the noncovalent complex of the same proteins (15). A sequence encoding the cleavage site for tobacco etch virus (TEV) protease (16) was introduced between the genes encoding EF-Tu and the $\beta$-subunit to avoid aggregation of the fusion protein. Gel filtration in a high salt buffer resolved TEV-digested preparations of both the core enzyme (EF-Ts:EF-Tu: $\beta$-subunit) and the holoenzyme (EF-Ts:EF-Tu: $\beta$-subunit:S1), into two peaks corresponding to a monomer and dimer of the $\mathrm{Q} \beta$ replicase (Fig. $1 A$ ) of the same subunit composition (Fig. S1A). Of these, only the dimer of the core replicase was crystallizable. The core dimer was virtually inconvertible to the monomer and vice versa, and no dimer formation was observed with the wild-type $\mathrm{Q} \beta$ replicase core (Fig. S1 $B$ and $C$ ). The specific activity of the dimeric and monomeric preparations as assayed in a poly $(\mathrm{C})$-directed reaction was about 10,000 units $/ \mathrm{mg}$ (Fig. S1D). The dimer and monomer showed similar thermal stabilities and temperature optima (Fig. S1 $E$ and $F$ ) as the wild-type core replicase. Also, the dimer and monomer were equally efficient in the amplification of RQ RNA (Fig. S1G).

Upon RNA binding, the monomer produced one slower migrating band during nondenaturing PAGE, whereas the dimer produced two bands, presumably containing one and two tem-

Author contributions: A.B.C., G.R.A., and C.R.K. designed research; R.T.K. and N.N.V. performed research; R.T.K., N.N.V., A.B.C., G.R.A., and C.R.K. analyzed data; and A.B.C. G.R.A., and C.R.K. wrote the paper

The authors declare no conflict of interest.

This article is a PNAS Direct Submission.

Data deposition: Coordinates and structure factors are deposited at the RCSB protein data bank as entry 3MMP.

${ }^{1}$ R.T.K. and N.N.V. contributed equally to this work.

${ }^{2}$ To whom correspondence should be addressed. E-mail: gra@mb.au.dk.

This article contains supporting information online at www.pnas.org/lookup/suppl/ doi:10.1073/pnas.1003015107/-/DCSupplemental. 


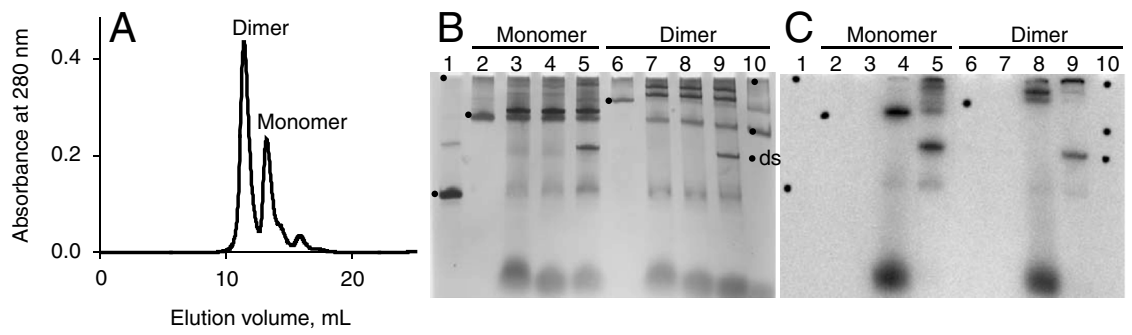

Fig. 1. Dimer and monomer of the $\mathrm{Q} \beta$ replicase core. $(A)$ Resolution of the TEV-digested fusion protein into dimer and monomer by gel filtration in a buffer containing $500 \mathrm{mM} \mathrm{NaCl}$. (B) Silver stained gel and $(C)$ its radioactivity pattern after nondenaturing PAGE of RQ135 RNA (lane 1), the monomer (lane 2), the dimer (lane 6), and complexes formed by the monomer and dimer in the presence of the RNA and GTP (lanes 3 and 7), plus CTP and [ $\alpha-{ }^{32}$ P]UTP (lanes 4 and 8) or CTP, $\left[\alpha^{-32}\right.$ P UTP, and ATP (lanes 5 and 9), and in the presence of GTP and no RNA (lane 10). The dots on the gel are radioactive markers identifying the positions of nonradioactive bands in C. Dot "ds" marks the position of the double-stranded RNA product.

plate molecules, respectively (Fig. $1 B$ ). Each of the RNA-bound bands become labeled in the presence of GTP, CTP, and $\left[\alpha{ }^{3}{ }^{32}\right.$ P $]$ UTP (Fig. $1 C$, lanes 4 and 8 ), when only a 5-nt-long product strand might have been synthesized on the $3^{\prime}$-terminal template sequence, $5^{\prime}$-...UAGCCC-3' (3). The fact that such a short product remained tightly bound during the long electrophoresis procedure suggests that each of the RNA-bound bands represents the closed conformation of the replicative complex (17). When all four NTPs were present providing for the synthesis of full length product, the label was separated into a double-stranded product and high molecular weight complexes, which tend to be larger in the case of the dimer (Fig. 1C, lanes 5 and 9). Thus, the dimer complex retains its integrity during RNA synthesis, although it partially dissociates into monomers in the presence of GTP. This dissociation does not relate to RNA synthesis, because it was also observed in the absence of template (Fig. $1 B$, lane 10) and no label migrated ahead of the dimer band upon initiation (Fig. 1C, lane 8). Hence, the crystallizable dimeric Q $\beta$ replicase core represents a fully active complex indistinguishable from either the monomer or the wild-type core complex by a number of functional criteria demonstrating the functional relevance of the structure.

Structure of the Core Replicase. X-ray diffraction data extending to a maximum resolution of $2.5 \AA$ (Table S1) were collected and the structure of the $\mathrm{Q} \beta$ core replicase was determined by molecular replacement. In the asymmetric unit of the crystal, two monomers (Fig. $2 A$ ) of the core replicase related by a twofold rotation symmetry axis are present (Fig. S2C) and may correspond to the dimer found in solution. We have traced the same 1,219 residues per monomeric core replicase. In both copies, disordered are the
EF-Ts residues 1-2, 283, and the histidine connecting it with EF-Tu; EF-Tu residues $1-8$ and $42-63$; and $\beta$-subunit residues $1-6,114-118,520-532$, and 574-589. The $\beta$-subunit (Fig. $2 B$ and Fig. S2D) has the appearance of a cupped right hand known from other polymerase structures (Fig. S3) (18) and can be divided into three domains: the palm, the thumb, and the fingers. Five conserved motifs, A-E (Fig. S4), with established functions in the catalytic mechanism are located in the palm domain (19). This domain is composed of two $\alpha$-helices packed against one face of a four-stranded antiparallel $\beta$-sheet containing motifs A, C, and D (Fig. S3F). These secondary structure elements are organized with the topology $\beta \alpha \beta \beta \alpha \beta$ also found in the RNA-recognition motif. A third helix is located on the opposite face of the four-stranded sheet, and this helix also packs against a small two-stranded, antiparallel $\beta$-sheet at the end of the palm domain containing the $\mathrm{E}$ motif. This sheet also forms the interface of the palm domain toward the thumb domain.

The thumb domain (Fig. $2 B$ and Figs. S2D and S4) consists of three segments: The first (residues 7-87) precedes the fingers domain and is $\alpha$-helical, whereas the second (residues 408-494) follows the palm domain. The third, C-terminal segment (residues $560-573$ ) contributes to the three-stranded $\beta$-sheet at the tip of the thumb domain, whereas the remaining 16 residues are disordered in agreement with mutational analysis showing that residues beyond 573 are dispensable (Table S2). The fingers domain (Fig. $2 B$ and Fig. S2D) of the $\beta$-subunit consists of a fourstranded, antiparallel $\beta$-sheets and nine $\alpha$-helices, and contains three segments: $(i)$ residues $88-253$ preceding the palm domain, (ii) residues 282-327 inserted between motifs A and B of the palm domain, and finally (iii) a single $\alpha$-helix containing residues
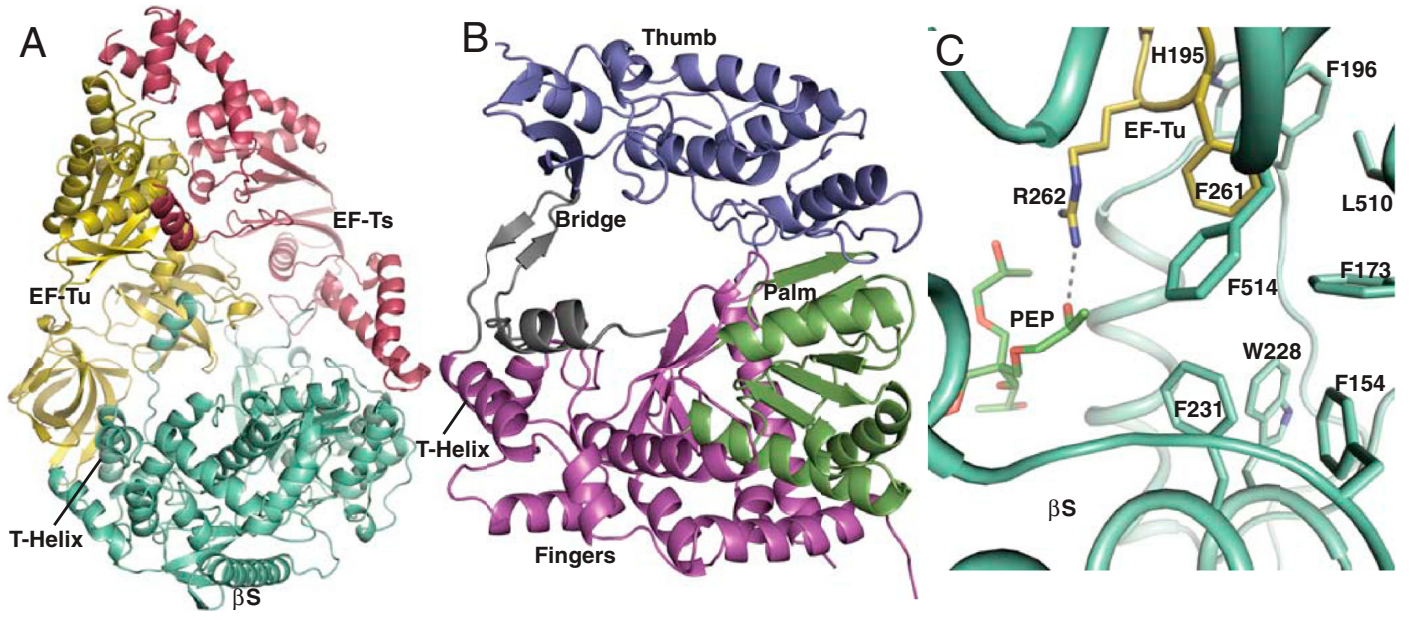

Fig. 2. Structure of the $\mathrm{Q} \beta$ replicase core complex. $(A)$ Cartoon representation of the monomeric core replicase containing $\beta$-subunit (Green, labeled " $\left.\beta S^{\prime \prime}\right)$ in complex with EF-Tu (Yellow) and EF-Ts (Dark Red). (B) The domains of the $\beta$-subunit. The thumb domain is colored blue, the palm domain green, the fingers domain magenta, and the bridge region gray. (C) The PEP (Green Sticks) binding site on the $\beta$-subunit; a hydrogen bond with Arg262 of EF-Tu (Yellow) is shown as a dashed line. Binding of PEP possibly stabilizes the interaction of EF-Tu Phe261 with the hydrophobic cluster in the $\beta$-subunit. 
505-518, which we will refer to as the T helix. The fingers domain contains a structurally conserved subdomain (residues 88-143, 208-253, and 282-327) that packs against the palm domain and contains secondary structure elements with a connectivity found in other RdRps as well (Fig. S3 $G-L$ ). In contrast, the residues 144-207 and the Thelix appear to be structurally unique compared to other RdRps.

In other RdRps, the F motif is found in the $\mathrm{N}$ terminal of their sequences, where it connects the thumb domain with the fingers domain, and the motif is possibly involved in template unwinding (19). This motif cannot be identified in the $\beta$-subunit by sequence alignment. In the $\beta$-subunit, the function of the $F$ motif is structurally fulfilled by the highly conserved loop 213-218 in the fingers domain with assistance from the loop 77-90 that connects the thumb and the fingers domain. The fingers domain of the $\beta$-subunit is also connected to the thumb domain through what we will refer to as the "bridge" (Fig. $2 B$ and Fig. S2D) region crossing from the thumb to the fingers domain and back again. The bridge region consists of two flexible segments, residues 497-504 and 520-559, which flank the T helix in the fingers domain (Fig. S4). The region 520-532 is disordered in our structure. A small, two-stranded antiparallel $\beta$-sheet in the bridge is suspended between the thumb and fingers domains approximately $30 \AA$ above the catalytic core structure of the palm domain. The single $\alpha$-helix in the bridge region is located between the $\mathrm{T}$ helix and the second $\beta$-strand of the bridge (Fig. $2 B$ ). Two other RdRp structures contain elements resembling the bridge region. In the RdRp from hepatitis $\mathrm{C}$ virus, a $\beta$-hairpin extends from the thumb domain towards the palm domain (20). It has been suggested to undergo a conformational change to accommodate the RNA between the thumb and the fingers domain, which could position the hairpin in a location similar to that of the bridge $\beta$-sheet in the $\mathrm{Q} \beta$ replicase. The second case is the $\lambda 3$ reovirus $\mathrm{RdRp}$, which has a C-terminal annular $\alpha$-helical structure, known as the bracelet domain (21). Intriguingly, the $\beta$-subunit bridge together with EF-Tu domains 2-3 also forms an annular structure with a hole of similar size and located in the same orientation (see below).

Alignment of RdRp sequences from the virus family Leviviridiae suggests two subclasses corresponding to the Allolevivirus genus, to which the $\mathrm{Q} \beta$ phage belongs, and the Levivirus genus (Figs. S4 and S5 $A-F$ ). In Levivirus, the polymerases are 30-50 residues shorter than in Allolevivirus because of deletions in especially the thumb domain (Figs. S4 and S5 $E$ and $F$ ). Comparison of the structure of the $\beta$-subunit with this alignment suggests that all Leviviridiae polymerases have a structure similar to that of the $\beta$-subunit from the $Q \beta$ phage. In particular, they will all have the bridge region, although the $\mathrm{Q} \beta$ protein has a longer bridge than all other Allolevivirus RdRps, which may be lacking the bridge $\alpha$-helix.

Intermolecular Contacts in the Monomeric and Dimeric Q $\mathbf{\beta}$ Replicase Core Complexes. The interface between the two $\beta$-subunits within the putative dimer of the core enzyme is substantial with a buried surface area of $1,770 \AA^{2}$ (Table S3). Residues 121-135 and $345-350$ contribute to the dimer interface between the $\beta$-subunits (Fig. S6F), and these are highly conserved in Allolevivirus. In addition to van der Waals interactions between the two $\beta$-subunits, residues Arg132 and Arg133 of each $\beta$-subunit form salt bridges with Asp348 from the opposing $\beta$-subunit (Fig. $3 A$ ). The dimer is further stabilized by minor EF-Tu:EF-Tu contacts involving residues 38-40 (Fig. S6G) located immediately prior to the switch I region.

The EF-Tu:EF-Ts: $\beta$-subunit complex forms a chair-shaped structure of maximum dimensions $116 \times 79 \times 80 \AA$, where the viral subunit forms the seat and host proteins the back of the chair (Fig. 2A). The chair has one armrest formed by the EF-Ts coiledcoil region (residues 187-226), which is in contact with the regions $62-64$ and $436-442$ of the $\beta$-subunit thumb domain (Fig $3 B$ and Fig. S6 $D$ and $E$ ), with the latter being completely conserved. EF-Tu:EF-Ts in the Q $\beta$ replicase complex superimpose with a rmsd of $1 \AA$ A over $592 \mathrm{C}^{\alpha}$ atoms onto the free complex from Research Collaboratory for Structural Bioinformatics (RCSB) entry $1 \mathrm{EFU}$ (22). Only the EF-Ts coiled-coil motif is significantly affected, and the interaction causes EF-Ts residues 190-217 in the coiled coil to rotate by $18^{\circ}$ compared to EF-Tu:EF-Ts. The interface between EF-Ts and the $\beta$-subunit is substantial with a buried surface area of $1,522 \AA^{2}$ (Table S3).

Even more extensive contacts are formed between the $\beta$-subunit and EF-Tu with a buried surface area of 3,766 $\AA^{2}$ (Table S3 and Fig. S6 $A$ and $B$ ). The most prominent interactions are formed between EF-Tu domain 2 and the fingers domain, which includes the insertion of the $\mathrm{T}$ helix into the binding pocket for the CCA-aminoacyl group of aa-tRNA bound to EF-Tu:GTP (23) (Fig $3 C-E$ ). In particular, Tyr509 of the $\beta$-subunit forms both hydrophobic interactions and a hydrogen bond with EF-Tu Glu259, and $\operatorname{Arg} 516$ of the $\beta$-subunit engages in a salt bridge with EF-Tu Glu215. The distant end of the $\beta$-subunit thumb domain is inserted between a region in EF-Tu domain 3 that also forms contacts with the aa-tRNA T stem (23) and the EF-Ts loop 233-239 (Fig. $3 F$ ). On the basis of the number of interactions, the region 481-491, not present in Levivirus, appears to play an important role in this interface involving all three proteins (Fig. $3 F$ ). A second conserved segment of the thumb domain, residues 566-573 neighboring the 481-491 region structurally, also interacts with both EF-Ts and EF-Tu. Finally, the $\alpha$-helix of the $\beta$-subunit bridge region packs between EF-Tu domains 1 and 3 in the proximity of the switch regions I and II (residues 80-100) (Fig S6H). The $\beta$-subunit:EF-Tu interface is additionally stabilized by a molecule of the precipitant pentaerythritol propoxylate 5/4 $\mathrm{PO} / \mathrm{OH}$ (PEP), which is trapped in a pocket formed by four helices in the fingers domain and the side chain of EF-Tu Arg262 that forms a hydrogen bond with PEP (Fig. 2C). The fixation of the EF-Tu arginine by PEP most likely results in increased hydrophobic interactions of the neighboring EF-Tu Phe261 with a hydrophobic cluster of six phenylalanine and one leucine side chains from the fingers domain (Fig. 2C), which keep the T helix in place for its interaction with the EF-Tu CCA pocket. A stabilizing effect of PEP is in agreement with its positive effect on replicase activity (Fig. S1D).

Regions of the $\beta$-Subunit with a Potential of Interacting with Substrates and Product. The locations of residues with a catalytic function during addition of NTP to the $3^{\prime}$ end of the product strand and residues creating the binding site for the transient templateproduct duplex are known from structures of initiating or elongating RdRps in complex with template, product, NTP, and metal ions (18). We have compared our apo structure with the structure of the Norwalk virus RdRp bound to CTP and product-template duplex (24) to identify regions of the $\beta$-subunit that are likely to interact with RNA, NTP, and metal ions during catalysis. On the basis of this comparison, the template is likely to enter through a channel formed within the fingers domain. It is bounded by a large loop containing residues $156-165$, as well as one face of the four-stranded antiparallel $\beta$-sheet in the fingers domain (Fig. $4 A$ and $B$ and Fig. S7). The $\beta$-subunit template channel is similar to those in the RdRps from Norwalk virus and hepatitis $\mathrm{C}$ virus (25). The putative NTP substrate entrance channel is located between residues 383-386 (from motif D) and 275-277 (in motif A) from the palm domain together with the segments 214-218 and 95-99 in the fingers domain (Fig. $4 A$ and $B$ and Fig. S7). The substrate channel is flanked by five conserved lysine/arginine side chains that are capable of coordinating the incoming NTP. At the catalytic site, Asp274 in motif A and Asp359Asp360 in motif $\mathrm{C}$ are expected to coordinate two $\mathrm{Mg}^{2+}$ ions that can mediate catalysis according to the two-metal-ion mechanism $(18,26)$. The strictly conserved Lys214 and Arg220 are likely to form electrostatic interactions with the NTP phosphates as well. Nucleic acid polymerases have been suggested to use as a general acid to protonate the pyrophosphate-leaving group, and in the 

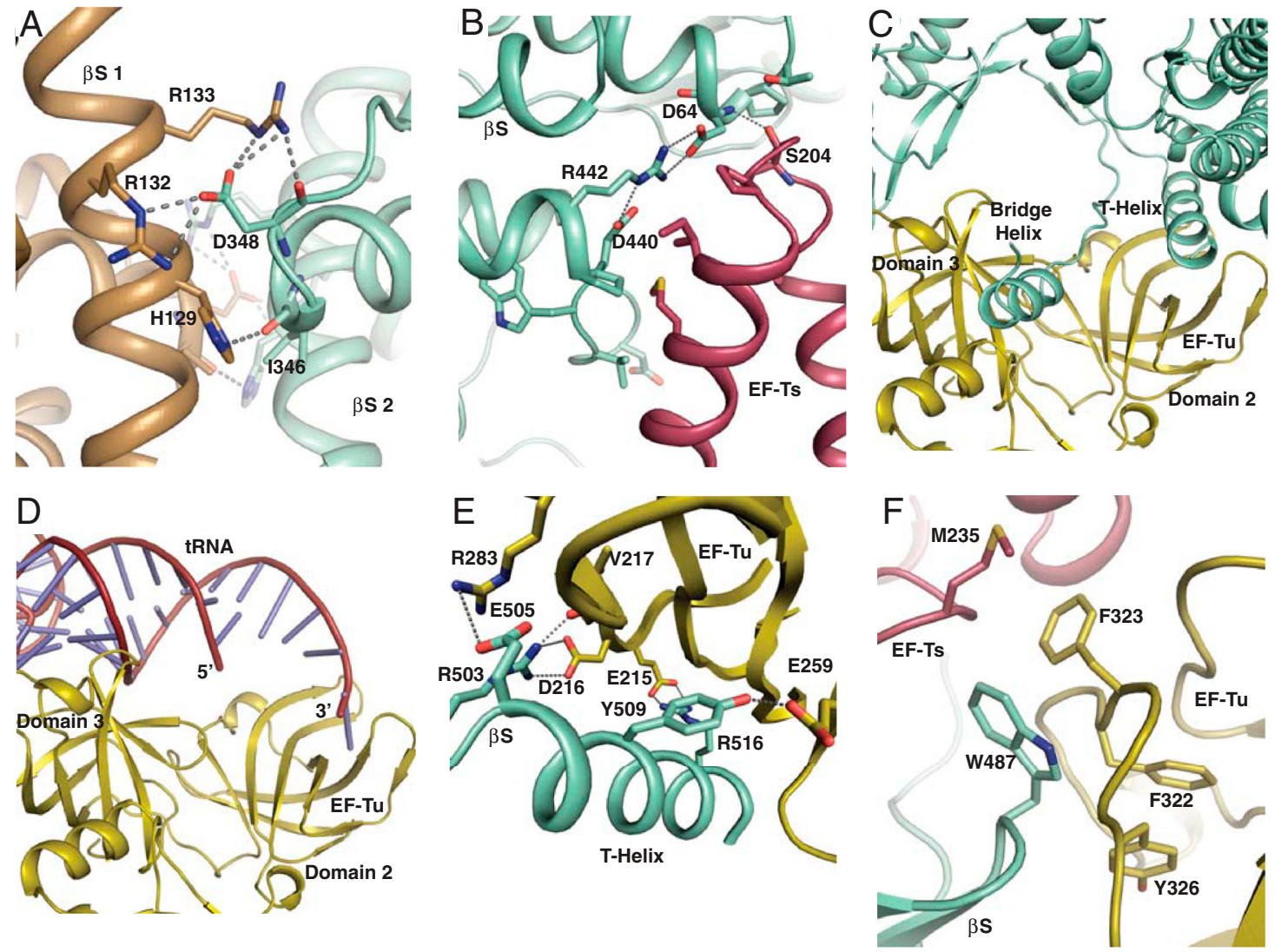

Fig. 3. Intermolecular contacts within the $\mathrm{Q} \beta$ replicase. Hydrogen bonds and electrostatic interactions are shown as dashed lines. $(A)$ Details of the $\beta$-subunit $(\beta S)$ : $\beta$-subunit interface. $(B)$ Contacts between the EF-Ts (Dark Red) coiled-coil motif and the $\beta$-subunit (Green) thumb domain. (C) The interface between the $\beta$-subunit and EF-Tu (Yellow) involving the Thelix and bridge helix from the $\beta$-subunit and domains 1 and 3 from EF-Tu. (D). The complex of EF-Tu and aa-tRNA in the same orientation as in $C$. (E) Close-up of the $\beta$-subunit T-helix interaction with EF-Tu domain 2 . (F) Insertion of the $\beta$-subunit thumb domain between EF-Tu domain 3 and EF-Ts.

polio virus RdRp Lys359 in motif D has been assigned this function (27). On the basis of our structure, we suggest that the strictly conserved Lys386 in motif $\mathrm{D}$ of the $\beta$-subunit can fulfill a similar role.

A large internal cavity in the $\beta$-subunit appears to be available for binding a product-template A-form RNA duplex as previously observed in RdRps from Picornaviridae and Caliciviridae (18). The base of this cavity is formed by the palm domain but flanked on each side by the thumb and the fingers domain (Fig. $4 A$ and $B$ and Fig. S7). The bridge limits the cleft above the catalytic center and is located at the periphery of the predicted path of the du-

\section{A}

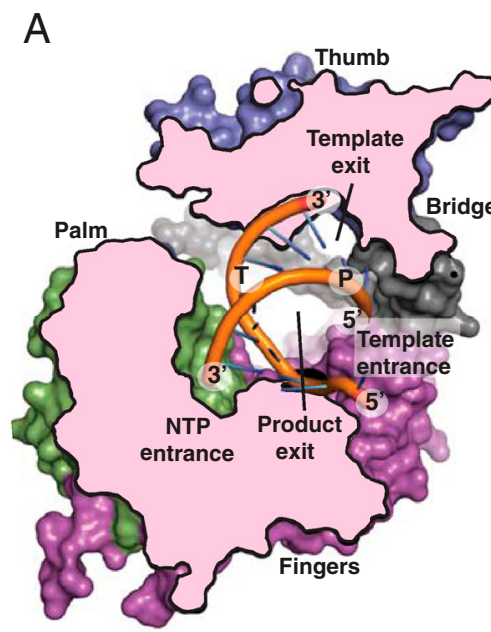

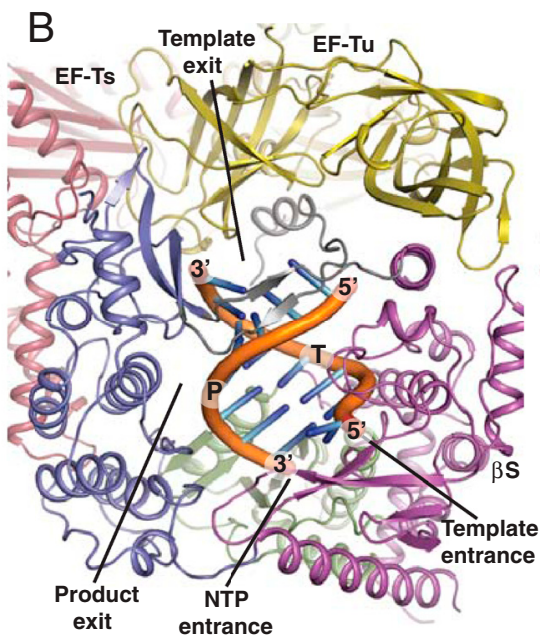

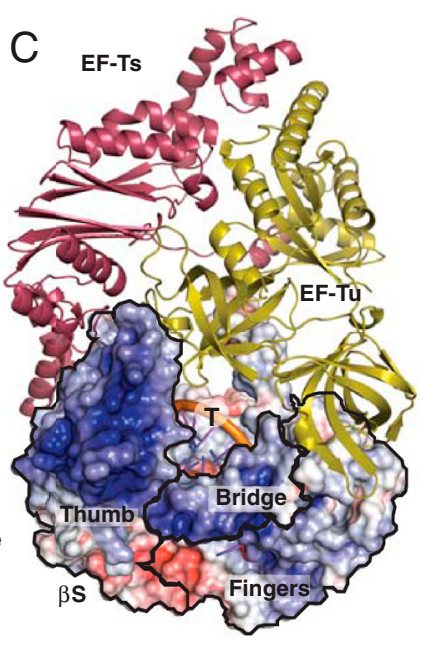

Fig. 4. RNA binding and surface properties of the $\beta$-subunit. The double-stranded RNA in the internal cavity of the $\beta$-subunit (colored as in Fig. $2 B$ ) was docked by comparison with the structure of the Norwalk virus RdRp, PDB ID code 3BSN. Template and product strand are labeled " $T$ " and "P," respectively, and 3' and 5' ends are labeled as well. $(A)$ Cross-section through the $\beta$-subunit displaying the suggested template and NTP entrance channels together with the template exit channel. $(B)$ Cartoon representation of the core replicase indicating the four putative channels. $(C)$ Surface representation displaying the electrostatic potential of the $\beta$-subunit colored according to charge (Blue $10 \mathrm{kt} / \mathrm{e}$, White 0, Red -10 kt/e) with EF-Tu and EF-Ts shown in cartoon mode. The positively charged blue surface patch containing elements of the bridge and thumb domains of the $\beta$-subunit is a possible binding site for the $\$ 1$ protein, template, and product. The thumb, bridge, and fingers domains of the $\beta$-subunit are indicated on the surface representation with a black outline. 
plex, suggesting an important function of the bridge as a strand separator. Coarse modeling indicates that the $5^{\prime}$ end of the product strand would collide with the $\beta$-sheet of the bridge after synthesis of 5-6 phosphodiester bonds. The product strand may thereby become single-stranded and exits the internal cavity before a duplex length of 6-7 base pairs is reached. One option is that it exits through the opening between the bridge, thumb, and fingers domains, but this already harbors the template entrance channel. Much more space is available in an opening between the palm and thumb domains, EF-Tu domain 3, and the EF-Ts coiled coil (Fig. $4 A$ and $B$ ). In contrast, the $3^{\prime}$ end of the template strand could maintain an A-form RNA conformation even after unwinding and pass through the annular hole between the bridge region, the thumb domain $\beta$-sheet, and EF-Tu domains 2-3 (Fig. 4 and Fig. S7). An exit path through an annular hole in the $\lambda 3$ bracelet has also been suggested for the reovirus RdRp and suggested to be accessible to both single- and double-stranded RNA (21), but, unless significant conformational changes occur between the apo state of our structure and the actual replicating state, the hole in the $\mathrm{Q} \beta$ replicase can accommodate only single-stranded RNA.

Putative Binding Sites for RNA and the S1 Protein. Mapping of the electrostatic potential onto the surface of the $\beta$-subunit identifies a rather large, positively charged and partly conserved patch covering the distant end of the thumb domain and the outside of the bridge $\beta$-sheet loop (Fig. $4 C$ and Fig. S5 $A-D$ ) with potential for interacting with a negatively charged macromolecule. Prime candidates are template/product RNA or the strongly acidic protein S1. The Q $\beta$ replicase holoenzyme can be dissociated into two enzymatically inactive complexes (28), S1: $\beta$-subunit and EF-Tu:EF-Ts, indicating that the main association of S1 with the $\mathrm{Q} \beta$ replicase complex occurs via the $\beta$-subunit. Binding of S1 at this positively charged patch would place S1 in close proximity to the suggested template entrance and exit holes.

\section{Discussion}

Maintenance of High Amplification Efficiency. The $Q \beta$ genome is amplified with extraordinary efficiency both in vivo and in vitro, which is partly achieved because the $\mathrm{Q} \beta$ replicase is able to utilize both the minus and the plus strands as a template, thus rendering exponential amplification possible $(29,30)$. In contrast, doublestranded RNA is rejected as a template (31). Thus, for an RNA strand to serve as a template in multiple rounds of RNA synthesis, extensive base pairing between template and product strands should be prevented. $Q \beta$ replicase is the only RdRp with a proven ability to prevent the unwound template and product strands from reannealing (31), and this capacity enables exponential RNA amplification (Fig. S1G). The explanation has remained an enigma, but our structure suggests two structural features that provide a credible solution to the problem. First, the bridge region is probably involved in unwinding the duplex between the template and the nascent part of the product when the duplex reaches a maximum size of 6-7 base pairs. Second, the strong, intrastrand secondary structures typical of efficient $Q \beta$ replicase templates (32) may assist the $\mathrm{Q} \beta$ replicase in obtaining the singlestranded state of template for subsequent cycles of replication. The separation between the proposed exit channels for template and product seems to favor formation of such intrastrand secondary structure relative to formation of extensive template-product duplex. The suggested encounter between RNA and the bridge region may in addition cause a conformational change that potentially could affect the interaction between the $\beta$-subunit and EF-Tu. Docking of the RNA duplex in the active sites and the suggested locations of the RNA entry/exit sites within the replicase dimer (Fig. S7F) does not support channeling of RNA between the two $\beta$-subunits in agreement with our functional studies (Fig. 1 and Fig. S1).
Functional Significance of Interactions Between the $\beta$-Subunit and Host Proteins. Our structure provides a unique example of a viral RdRp complex containing host proteins, and features of this complex may apply to other cases, in particular to those viral RdRp complexes containing the eukaryotic homologue of EF-Tu, eEF1A. The basic catalytic machinery of the $\beta$-subunit is not in direct contact with the host proteins in agreement with the ability of the viral subunit to function in the elongation phase of RNA replication in their absence (33). Quantitatively, the interface between the $\beta$-subunit and EF-Ts is relatively small compared to the $\beta$-subunit:EF-Tu interface. Thus, it is interesting to consider why the $\beta$-subunit has evolved to depend on the EF-Tu:EF-Ts complex rather than on EF-Tu alone. In the bacterial cell, all EF-Ts is expected to be in complex with EF-Tu, whereas only 10-20\% of the EF-Tu is found in complex with EF-Ts (34). The majority of the remaining EF-Tu is likely to be in complex with abundant aa-tRNA. Hence, if the $\beta$-subunit depended only on EF-Tu, it would encounter a strong, direct competition from aa-tRNA for the binding to EF-Tu. However, the vital importance of the coiled-coil domain of EF-Ts for formation of the Q $\beta$ replicase complex (9) and the observed interaction of the $\beta$-subunit with the coiled coil shows that virus also takes direct advantage of the presence of EF-Ts.

The existence of a correlation between the ability of EF-Tu for binding tRNA and its function within the $\mathrm{Q} \beta$ replicase has been a matter of dispute. Our structure revives this debate, because the CCA-binding pocket of EF-Tu interacts directly with the $\beta$-subunit T helix. Originally, the replacement of endogenous EF-Tu with chemically or enzymatically modified variants incapable of binding tRNA was found not to affect the functionality of EF-Tu in the $\mathrm{Q} \beta$ replicase complex (7). More recent studies of $\mathrm{Q} \beta$ replicase complexes containing mutant species of EF-Tu (Table S2) with defects in tRNA binding showed a direct correlation between the tRNA-binding capacity of the mutants and their ability to sustain replication when part of a $\mathrm{Q} \beta$ replicase complex (35), which is in agreement with our structure showing the binding of the $\beta$-subunit $\mathrm{T}$ helix to the EF-Tu CCA-binding pocket. A striking consequence of this interaction is that the host is unlikely to evolve resistance towards $\mathrm{Q} \beta$ by mutations in the aminoacyl-binding pocket, because this could interfere with its normal function A close parallel is the recognition of elongation factor 2 by pseudomonas exotoxin $\mathrm{A}$ at a site involved in contacts with the decoding center of the ribosome (36). Another intriguing question raised by the structure, and in particular the proposed location of the template exit channel, is whether the template CCA-3 end at some point competes with the $\beta$-subunit $\mathrm{T}$ helix for binding to the CCA-aminoacyl pocket of EF-Tu.

Concluding Remarks. The elucidation of the function of the host proteins in viral RdRp complexes is of potential importance in drug development against pathogenic viruses. Here we provide a description at the atomic level of a viral RdRp complex containing host proteins. In our case, the basic catalytic machinery is well separated from the host proteins, which seem to provide a stabilizing scaffold for the $\beta$-subunit and perhaps provide interaction sites for the template both before and after initiation of replication. $Q \beta$ replicase is the most efficient in vitro system for nucleic acid amplification, far more efficient than PCR or isothermal amplification systems (17). However, the utilization of $\mathrm{Q} \beta$ replicase for amplification of desired sequences has yet to be realized because of its puzzling and extraordinary template specificity requiring neither promoters nor primers $(7,8)$. Although the described structure does not provide an immediate solution to this problem, it paves a way for a rational approach towards reaching this goal.

\section{Materials and Methods}

Detailed experimental procedures for all techniques used are given in SI Methods. 
Expression and Purification. The expression vector pBAD33Ts-Tu- $\beta$-3 (15) was modified to insert a TEV protease cleavage site in the fusion protein EF-Ts-EFTu-TEV- $\beta$ S-6xHis. Escherichia coli BL21 (DE3) transformed with the resulting plasmid was grown in LB medium and induced with L-arabinose. Harvested cells were lysed by sonication. The fusion protein was purified by $\mathrm{Ni}^{2+}$ chelate chromatography and subsequently digested by TEV protease. The cleaved fusion protein was further purified by hydrophobic interaction chromatography and gel filtration.

Formation of Replicative Complexes. Formation of replicative complexes was detected by a gel shift assay. The monomeric or dimeric form of $\mathrm{Q} \beta$ replicase was incubated with a 139-nt-long derivative (17) of the minus strand of RQ135 ${ }^{-1}$ RNA (3) in reaction buffer containing GTP and, where indicated, CTP and $\alpha-{ }^{32}$ P UTP, with or without ATP. The reaction conditions were adjusted to keep the molar amount of RNA product lower than the amount of enzyme. Subsequently, the samples were subjected to nondenaturing electrophoresis through an $8 \%$ polyacrylamide gel for 2 hours at $10-12^{\circ} \mathrm{C}$ Subsequently, the gel was silver stained and dried. ${ }^{32} \mathrm{P}$-labeled bands were revealed with a phosphor storage system and quantified by measuring intensities of the resulting bands.

1. Ahlquist P, Noueiry AO, Lee WM, Kushner DB, Dye BT (2003) Host factors in positivestrand RNA virus genome replication. J Virol 77:8181-8186.

2. Su Q, Schuppli D, Tsui HCT, Winkler ME, Weber H (1997) Strongly reduced phage $\mathrm{Q} \beta$ replication, but normal phage $\mathrm{MS} 2$ replication in an Escherichia coli $\mathrm{K} 12$ mutant with inactivated $Q \beta$ host factor (hfq) gene. Virology 227:211-214.

3. Munishkin AV, et al. (1991) Efficient templates for $\mathrm{Q} \beta$ replicase are formed by recombination from heterologous sequences. J Mol Biol 221:463-472.

4. Kamen R, Kondo M, Römer W, Weissmann C (1972) Reconstitution of Q $\beta$ replicase lacking subunit with protein-synthesis-interference factor i. Eur J Biochem 31:44-51.

5. Weissmann C (1974) The making of a phage. FEBS Lett 40:S10-18.

6. Tretheway DM, Yoshinari S, Dreher TW (2001) Autonomous role of $3^{\prime}$-terminal CCCA in directing transcription of RNAs by Q $\beta$ replicase. J Virol 75:11373-11383.

7. Blumenthal T, Carmichael GG (1979) RNA replication: Function and structure of Q replicase. Annu Rev Biochem 48:525-548.

8. Brown D, Gold L (1996) RNA replication by Q $\beta$ replicase: A working model. Proc Natl Acad Sci USA 93:11558-11562.

9. Karring $H$, et al. (2004) Q $\beta$-phage resistance by deletion of the coiled-coil motif in elongation factor Ts. J Biol Chem 279:1878-1884.

10. Schuppli D, et al. (1997) Altered 3'-terminal RNA structure in phage Q $\beta$ adapted to host factor-less Escherichia coli. Proc Natl Acad Sci USA 94:10239-10242.

11. Johnson CM, Perez DR, French R, Merrick WC, Donis RO (2001) The NS5A protein of bovine viral diarrhoea virus interacts with the alpha subunit of translation elongation factor-1. J Gen Virol 82:2935-2943.

12. Harris KS, et al. (1994) Interaction ofpoliovirus ppolypeptide 3 CDpro with the $5^{\prime}$ and 3 termini of the poliovirus genome. Identification of viral and cellular cofactors needed for efficient binding. J Biol Chem 269:27004-27014.

13. Yamaji $Y$, et al. (2006) In vivo interaction between Tobacco mosaic virus RNAdependent RNA polymerase and host translation elongation factor 1A. Virology 347:100-108.

14. Ortin J, Parra F (2006) Structure and function of RNA replication. Annu Rev Microbiol 60:305-326.

15. Kita $\mathrm{H}$, et al. (2006) Functional $\mathrm{Q} \beta$ replicase genetically fusing essential subunits $E F-T$ and EF-Tu with beta-subunit. J Biosci Bioeng 101:421-426.

16. Carrington JC, Dougherty WG (1988) A viral cleavage site cassette: Identification of amino acid sequences required for tobacco etch virus polyprotein processing. Proc Natl Acad Sci USA 85:3391-3395.

17. Ugarov VI, Demidenko AA, Chetverin AB (2003) Q $\beta$ replicase discriminates between legitimate and illegitimate templates by having different mechanisms of initiation. J Biol Chem 278:44139-44146.

18. Ng KK, Arnold JJ, Cameron CE (2008) Structure-function relationships among RNAdependent RNA polymerases. Curr Top Microbiol Immunol 320:137-156.

19. Bruenn JA (2003) A structural and primary sequence comparison of the viral RNAdependent RNA polymerases. Nucleic Acids Res 31:1821-1829.
Structure Determination. Crystals were grown by vapor diffusion at $4{ }^{\circ} \mathrm{C}$ with a reservoir buffer containing $0.2 \mathrm{M} \mathrm{KCl}, 0.05 \mathrm{M}$ Hepes- $\mathrm{NaOH} \mathrm{pH} 7.5$, and $27-30 \% \mathrm{vol} / \mathrm{vol}$ PEP. Reservoir buffer was mixed 1:1 with dimeric core replicase (36 mg/mL). Crystals were soaked prior to flash freezing in a buffer containing $0.2 \mathrm{M} \mathrm{KCl}, 0.05 \mathrm{M}$ Hepes- $\mathrm{NaOH} \mathrm{pH} 7.5$, and 35\% PEP. Diffraction data were processed with XDS (37). Two copies of the EF-Tu:EF-Ts complex were located with PHASER (38), and RESOLVE located significant parts of the $\beta$-subunits after density modification. In an iterative manner, the remaining parts were build in COOT (39) and the resulting model refined with PHENIX.REFINE (40)

ACKNOWLEDGMENTS. We are grateful to K.M. Nielsen and G. Hartvigsen for excellent technical assistance, the staffs at European Synchrotron Radiation Facility and Swiss Light Source beam lines for help with data collection, M. Behrens for small angle X-ray scattering analysis, and M. Blaise and L. Sanderson for discussions. G.R.A. was supported by the Danish Science Research Council, Danscatt, the Vilhelm Petersen foundation, the Danish National Research Foundation, and a Hallas-Møller stipend from the Novo-Nordisk foundation. A.B.C. was supported by the Russian Foundation for Basic Research and the Molecular and Cell Biology Program of the Russian Academy of Sciences. C.R.K. was supported by the Danish Science Research Council.

20. Bressanelli S, et al. (1999) Crystal structure of the RNA-dependent RNA polymerase of hepatitis C virus. Proc Natl Acad Sci USA 96:13034-13039.

21. Tao Y, Farsetta DL, Nibert ML, Harrison SC (2002) RNA synthesis in a cage-Structural studies of reovirus polymerase $\lambda 3$. Cell 111:733-745.

22. Kawashima T, Berthet-Colomunas C, Wulff M, Cusack S, Leberman R (1996) The structure of the Escherichia coli EF-Tu . EF-Ts complex at $2.5 \AA$ resolution. Nature 379:511-518

23. Nissen P, et al. (1995) Crystal structure of the ternary complex of Phe-tRNAPhe, EF-Tu and a GTP analog. Science 270:1464-1472.

24. Zamyatkin DF, et al. (2008) Structural insights into mechanisms of catalysis and inhibition in Norwalk virus polymerase. J Biol Chem 283:7705-7712.

25. Bressanelli S, Tomei L, Rey FA, De Francesco R (2002) Structural analysis of the hepatitis C virus RNA polymerase in complex with ribonucleotides. J Virol 76:3482-3492.

26. Steitz TA (1998) A mechanism for all polymerases. Nature 391:231-232.

27. Castro C, et al. (2009) Nucleic acid polymerases use a general acid for nucleotidyl transfer. Nat Struct Mol Biol 16:212-218.

28. Kamen R (1970) Characterization of the subunits of Q $\beta$ replicase. Nature 228:527-533.

29. Dobkin C, Mills DR, Kramer FR, Spiegelman S (1979) RNA replication: Required intermediates and the dissociation of template, product, and $\mathrm{Q} \beta$ replicase. Biochemistry 18:2038-2044.

30. Chetverin AB (2004) Replicable and recombinogenic RNAs. FEBS Lett 567:35-41.

31. Weissmann C, Feix G, Slor H (1968) In vitro synthesis of phage RNA: The nature of the intermediates. Cold SH Q B 33:83-100.

32. Brown D, Gold L (1995) Selection and characterization of RNAs replicated by Q $\beta$ replicase. Biochemistry 34:14775-14782.

33. Landers TA, Blumenthal T, Weber K (1974) Function and structure in ribonucleic acid phage Q $\beta$ ribonucleic acid replicase. J Biol Chem 249:5801-5808.

34. Neuhard J, Nygaard P (1987) Purines and pyrimidines. Escherichia coli and Salmonella typhimurium Cellular and Molecular Biology, eds JL Ingraham et al. (Am Soc Microbiology, Washington, DC), Vol 1, pp 445-473.

35. Mathu SGJ, Knudsen CR, van Duin J, Kraal B (2003) Isolation of Q $\beta$ polymerase complexes containing mutant species of elongation factor Tu. J Chromatogr B 786:279-286.

36. Jorgensen R, et al. (2005) Exotoxin A-eEF2 complex structure indicates ADP ribosylation by ribosome mimicry. Nature 436(7053):979-984.

37. Kabsch W (2001) XDS. International Tables for Crystallography, eds MG Rossmann and E Arnold (Kluwer Academic, Dordrecht), Vol F.

38. McCoy AJ (2007) Solving structures of protein complexes by molecular replacement with Phaser. Acta Crystallogr D 63:32-41.

39. Emsley P, Cowtan K (2004) Coot: Model-building tools for molecular graphics. Acta Crystallogr D 60:2126-2132.

40. Adams PD, et al. (2002) PHENIX: Building new software for automated crystallographic structure determination. Acta Crystallogr D 58:1948-1954. 


\section{Supporting Information}

\section{Kidmose et al. 10.1073/pnas.1003015107}

\section{SI Text}

Details of Materials and Methods. Expression and purification. The expression vector pBAD33Ts-Tu- $\beta$-3 was kindly provided by Tetsuya Yomo, Osaka University (1). The sequence encoding the tobacco etch virus (TEV) site positioned between the genes encoding EF-Tu and the viral $\beta$-subunit was introduced using the Stratagene Quik Change II site-directed mutagenesis kit. Forward and reverse primers had the sequences 5'-GGTGGAGGCGGTGAGAATCTTTATTTTCAGTCAGGCGGAGGTG$3^{\prime}$ and 5'-CACCTCCGCCTGACTGAAAATAAAGATTCTCACCGCCTCCACC-3', respectively. The resulting plasmid is denoted pBAD33Ts-Tu-TEV- $\beta-3$ and the encoded protein is named EF-Ts-EF-Tu-TEV- $\beta \mathrm{S}-6 \mathrm{xHis}$. The expression vector pBAD33Ts-Tu-TEV- $\beta-3$ was transformed into the Escherichia coli strain BL21 (DE3). LB medium containing $34 \mu \mathrm{g} / \mathrm{mL}$ chloramphenicol was inoculated with $1.25 \%$ of an overnight culture of the transformed strain. At an $\mathrm{OD}_{600}$ of 0.8 the culture grown at $37^{\circ} \mathrm{C}$ was induced with $0.2 \%$ wt/vol L-arabinose for 3.5 hours. Harvested cells were resuspended in $2 \mathrm{~mL}$ lysis buffer (20\% glycerol, $0.1 \mathrm{M} \mathrm{NaH}_{2} \mathrm{PO}_{4} \mathrm{pH} 8.0,0.5 \mathrm{M} \mathrm{NaCl}, 5 \mathrm{mM} \mathrm{MgCl} 2,1 \mathrm{mM}$ PMSF, $5 \mathrm{mM} \beta$-mercaptoethanol, and $0.005 \%$ Tween 20 ) per gram of cells and lysed by sonication followed by ultracentrifugation at $256.000 \times g$ at $4{ }^{\circ} \mathrm{C}$ for 75 minutes. The resulting supernatant was filtrated through a $1.0 \mu \mathrm{m}$ filter and loaded on a $5-\mathrm{mL}$ HIS-trap high performance column (GE Healthcare) equilibrated in His-column buffer A $(20 \%$ glycerol, $0.1 \mathrm{M}$ Tris- $\mathrm{HCl}$ pH 7.6, $0.5 \mathrm{M} \mathrm{NaCl}, 5 \mathrm{mM} \mathrm{MgCl} 2,1 \mathrm{mM}$ PMSF, $5 \mathrm{mM} \beta$-mercaptoethanol, and $20 \mathrm{mM}$ imidazole). The column was washed in His-column buffer A and bound protein was eluted by a linear gradient of imidazole from $20-250 \mathrm{mM}$. Relevant fractions were pooled and TEV protease was added, and the sample was left overnight at $4{ }^{\circ} \mathrm{C}$. The TEV-cleaved fusion protein, denoted EF-Ts-EF-Tu: $\beta S-6 x H i s$, was added three volumes of hydrophobic interaction chromatography (HIC)-buffer A $\left(40 \%\left(\mathrm{NH}_{4}\right)_{2} \mathrm{SO}_{4}\right.$, $50 \mathrm{mM}$ Tris- $\mathrm{HCl} \mathrm{pH} 7.6,5 \mathrm{mM} \mathrm{MgCl}_{2}, 0.5 \mathrm{mM}$ DTT, $1 \mathrm{mM}$ EDTA) and loaded on a $9 \mathrm{~mL}$ Source-15 isopropyl column (GE Healthcare) preequilibrated in HIC-buffer A. The column was washed with $25 \%\left(\mathrm{NH}_{4}\right)_{2} \mathrm{SO}_{4}$ and eluted by a linear gradient from $25-15 \%\left(\mathrm{NH}_{4}\right)_{2} \mathrm{SO}_{4}$. Pooled fractions were loaded on a $120 \mathrm{~mL}$ Superdex 200 (GE Healthcare) gel filtration column equilibrated in $0.5 \mathrm{M} \mathrm{NaCl}, 20 \mathrm{mM}$ Tris- $\mathrm{HCl} \mathrm{pH}$ 7.8, $1 \mathrm{mM}$ DTT. Peaks corresponding to either monomeric or dimeric EF-Ts-EF-Tu:BS-6xHis with or without bound, endogenous S1 were pooled separately and concentrated to approximately $36 \mathrm{mg} / \mathrm{mL}$ as measured by absorption at $280 \mathrm{~nm}$. The molar concentration of the $\mathrm{Q} \beta$ replicase core preparations was determined by using the value of $A_{0.1 \%}=0.767$, as calculated by ProtParam (http://au.expasy.org/tools/protparam.html).

RNA templates. Poly $(\mathrm{C})$ (Amersham Biosciences) was used for standard Q $\beta$ replicase activity assays (2). A previously described 139-nt-long derivative (3) of the minus strand of RQ135 ${ }^{-1}$ RNA (4) was used for exploring the ability of $Q \beta$ replicase preparations to amplify RNAs and to form replicative complexes.

\section{Gel filtration.}

Gel filtration of $\mathrm{Q} \beta$ replicase preparations was performed using a $1 \times 30 \mathrm{~cm}$ Superdex 200 column connected to an AKTAprime plus liquid chromatography system (GE Healthcare), in buffer containing $20 \mathrm{mM}$ Tris- $\mathrm{HCl} \mathrm{pH} 7.5,1 \mathrm{mM}$ EDTA, $5 \mathrm{mM}$ $\mathrm{MgCl}_{2}, 5 \mathrm{mM} \beta$-mercaptoethanol, and $50 \mathrm{mM}$ or $500 \mathrm{mM} \mathrm{NaCl}$ as indicated.

\section{$Q \beta$ replicase activity.}

$\mathrm{Q} \beta$ replicase activity was assayed as a poly $(\mathrm{C})$-directed synthesis of poly $(\mathrm{G})(2)$ at $30^{\circ} \mathrm{C}$ (unless otherwise specified) in $10-\mu \mathrm{L}$ aliquots containing reaction buffer (100 mM Hepes- $\mathrm{NaOH} \mathrm{pH}$ 7.5, $10 \mathrm{mM} \mathrm{MgCl} 2,1 \mathrm{mM}$ EDTA), $0.5 \mu \mathrm{g}$ of a $\mathrm{Q} \beta$ replicase preparation (which added to the buffer $50 \mathrm{mM} \mathrm{NaCl}$, as well as $1 / 10$ concentration of other components contained in the gel filtration buffer $), 0.1 \mathrm{mg} / \mathrm{mL}$ poly $(\mathrm{C})$, and $0.2 \mathrm{mM}\left[{ }^{3} \mathrm{H}\right] \mathrm{GTP}(25,000 \mathrm{cpm} /$ nmol, Amersham Biosciences). Where indicated, pentaerythritol propoxylate $(5 / 4 \mathrm{PO} / \mathrm{OH})(\mathrm{PEP})$ was also present at the specified concentration. After incubation for $1 \mathrm{~min}$ (during which the reaction kinetics remained linear), the reaction was terminated by adding $5 \mu \mathrm{L}$ of $30 \mathrm{mM}$ EDTA and transferring the test tube on ice. The sample was then applied to a $1 \times 1 \mathrm{~cm}$ piece of Hybond $\mathrm{N}$ nylon membrane (Amersham Biosciences). The membrane was dried, washed 3 times for $3 \mathrm{~min}$ in a cold $\left(4^{\circ} \mathrm{C}\right)$ solution containing $3 \% \mathrm{H}_{3} \mathrm{PO}_{4}, 20 \mathrm{mM} \mathrm{Na}_{2} \mathrm{P}_{2} \mathrm{O}_{7}, 1 \mathrm{mM}$ EDTA, and once for $3 \mathrm{~min}$ in cold $75 \%$ ethanol ( $1 \mathrm{~mL}$ of a solution was used per membrane). After drying, the membrane was placed in $2.5 \mathrm{~mL}$ of a scintillation cocktail [0.02\% 1,4-bis(5-phenyl-2-oxazolyl)benzene, $0.4 \%$ 2,5-dephenyloxazole in toluene], and its radioactivity was determined using a Beckman LS 6500 counter. Specific activity of the enzyme was expressed in nmoles of GMP incorporated for $10 \mathrm{~min}$ at $30^{\circ} \mathrm{C}$ into the acid-insoluble material [the unit definition of $\mathrm{Q} \beta$ replicase (2)] per $1 \mathrm{mg}$ of protein.

\section{Temperature inactivation.}

Temperature inactivation of the $\mathrm{Q} \beta$ replicase preparations was performed in $8 \mu \mathrm{L}$ of the $1.25 \times$ reaction buffer $(125 \mathrm{mM}$ Hepes- $\mathrm{NaOH}$ pH 7.5, $12.5 \mathrm{mM} \mathrm{MgCl}_{2}, 1.25$ mM EDTA) containing $0.5 \mu \mathrm{g}$ of the enzyme during $10 \mathrm{~min}$ at the indicated temperature, followed by $30 \mathrm{~s}$ at $30^{\circ} \mathrm{C}$. Thereafter each sample was mixed with $2 \mu \mathrm{L}$ of a solution containing poly $(\mathrm{C})$ and $\left[{ }^{3} \mathrm{H}\right] \mathrm{GTP}$ to a final concentration of $0.1 \mathrm{mg} / \mathrm{mL}$ and $0.2 \mathrm{mM}$, respectively, and the residual $\mathrm{Q} \beta$ replicase activity was assayed as above.

\section{RNA amplification.}

RNA amplification was carried out at $30^{\circ} \mathrm{C}$ in the reaction buffer (see above) containing $1 \mathrm{mM}$ each of ATP, CTP, and GTP, $1 \mathrm{mM}$ $\left[\alpha-{ }^{32} \mathrm{P}\right] \mathrm{UTP}(1 \mathrm{MBq} / \mu \mathrm{mol}$, Institute of Bioorganic Chemistry), $0.5 \mathrm{nM}$ RQ135 RNA, and $100 \mathrm{nM}$ monomer equivalent of a $\mathrm{Q} \beta$ replicase preparation. At the indicated time points, $10-\mu \mathrm{L}$ aliquots were withdrawn, mixed with $5 \mu \mathrm{L}$ of $30 \mathrm{mM}$ EDTA, and placed on ice. Each sample was extracted with $15 \mu \mathrm{L}$ of phenol/chloroform $(1: 1, \mathrm{vol} / \mathrm{vol})$, and $10 \mu \mathrm{L}$ of the aqueous phase was subjected to nondenaturing PAGE (3). After silver staining (5), the gels were dried on a filter paper. The ${ }^{32} \mathrm{P}$-labeled RNA bands were revealed using a Cyclone ${ }^{\mathrm{TM}}$ phosphor storage system (Packard Instrument) and quantified by measuring the band intensity on 16-bit TIFF images using the OptiQuant ${ }^{\mathrm{TM}}$ Image Analysis Software (Packard Instrument).

\section{Formation of replicative complexes.}

Formation of replicative complexes was detected by a gel shift assay. One pmol of monomer equivalent of the monomer or dimer was incubated at $22^{\circ} \mathrm{C}$ for 10 min with 0.25 pmol of RQ135 RNA (premelted in $1 \mathrm{mM}$ EDTA) in $10 \mu \mathrm{L}$ of the reaction buffer (see above) containing $1 \mathrm{mM}$ GTP and, where indicated, $10 \mu \mathrm{M}$ CTP and $3 \mu \mathrm{M}\left[\alpha-{ }^{32} \mathrm{P}\right] \mathrm{UTP}$, with or without $10 \mu \mathrm{M}$ ATP. Specific activity of $\left[\alpha^{32} \mathrm{P}\right] \mathrm{UTP}$ was $0.3 \mathrm{MBq} / \mathrm{nmol}$ in the reactions without ATP and $0.01 \mathrm{MBq} / \mathrm{nmol}$ in the reactions with ATP. The concentration of UTP $(3 \mu \mathrm{M})$ allowed only a few replication 
rounds to occur and to keep the molar amount of RNA product lower than the amount of enzyme. After the addition of $1 \mu \mathrm{L}$ of the sample buffer $(50 \%$ glycerol, $0.05 \%$ bromophenol blue, $0.05 \%$ xylenecyanol, $1 \mathrm{mM}$ EDTA) and chilling on ice for $20 \mathrm{~min}$, the samples were subjected to nondenaturing electrophoresis through a $8 \%$ polyacrylamide gel during $2 \mathrm{~h}$ at $10-12$ ${ }^{\circ} \mathrm{C}$ in buffer TBE (89 mM Tris base, $89 \mathrm{mM}$ boric acid, $2 \mathrm{mM}$ EDTA) containing $10 \%$ glycerol and $3 \mathrm{mM} \mathrm{MgCl}_{2}$. The gel was stained with silver (5) and dried, and ${ }^{32} \mathrm{P}$-labeled bands were revealed as above.

Structure determination. Plate-shaped crystals were grown by vapor diffusion in sitting drops at $4{ }^{\circ} \mathrm{C}$ with a reservoir buffer containing $0.2 \mathrm{M} \mathrm{KCl}, 0.05 \mathrm{M}$ Hepes-NaOH pH 7.5, and 27-30\% vol/vol PEP The protein sample consisted of $1 \mu \mathrm{L}$ EF-Ts-EF-Tu $\cdot \beta \mathrm{S}-6 \mathrm{xHi}$ $(36 \mathrm{mg} / \mathrm{mL})$ added a two molar surplus of guanosine- $5^{\prime}-[(\beta, \gamma)$-imido]triphosphate (GDPNP) and was mixed with $1 \mu \mathrm{L}$ of reservoir buffer. Crystals were soaked prior to flash freezing in a buffer containing $0.2 \mathrm{M} \mathrm{KCl}, 0.05 \mathrm{M}$ Hepes-NaOH pH 7.5, and 35\% PEP. Diffraction data were collected at the European Synchrotron Radiation Facility (Table S1) and processed with XDS (6). Initial model phases were obtained by using the structure (Research Collaboratory for Structural Bioinformatics entry 1EFU) of the EF-Tu:EF-Ts complex (coiled-coil motif of EF-Ts removed) as search model in molecular replacement with the program PHASER (7), which identified two copies of the search model. An improved electron density was obtained by density modification with CNS (8), and the resulting phases were input to RESOLVE (9),

1. Kita $\mathrm{H}$, et al. (2006) Functional $Q \beta$ replicase genetically fusing essential subunits EF-Ts and EF-Tu with beta-subunit. J Biosci Bioeng 101:421-426.

2. Kamen $R$ (1972) A new method for the purification of $Q \beta$ RNA-dependent RNA polymerase. Biochim Biophys Acta 262:88-100.

3. Ugarov VI, Demidenko AA, Chetverin AB (2003) Q $\beta$ replicase discriminates between legitimate and illegitimate templates by having different mechanisms of initiation. J Biol Chem 278:44139-44146.

4. Munishkin AV, et al. (1991) Efficient templates for Q $\beta$ replicase are formed by recombination from heterologous sequences. J Mol Biol 221:463-472.

5. Igloi GL (1983) A silver stain for the detection of nanogram amounts of tRNA following two-dimensional electrophoresis. Anal Biochem 134:184-188.

6. Kabsch W (2001) XDS. International Tables for Crystallography, eds Rossmann MG, Arnold E (Kluwer Academic, Dordrecht), Vol F.

7. McCoy AJ (2007) Solving structures of protein complexes by molecular replacement with Phaser. Acta Crystallogr D 63:32-41.

8. Brunger AT, et al. (1998) Crystallography \& NMR system: A new software suite for macromolecular structure determination. Acta Crystallogr D 54:905-921.

9. Terwilliger TC (2003) Automated main-chain model building by template matching and iterative fragment extension. Acta Crystallogr D 59(Pt 1):38-44.

10. Emsley P, Cowtan K (2004) Coot: Model-building tools for molecular graphics. Acta Crystallogr D 60:2126-2132. which located significant parts for the replicase subunits. From this point, the model was improved in an iterative manner by phase calculation, density modification, and rebuilding. Upon convergence of this cycle, one copy of the $\mathrm{Q} \beta$ core replicase was rebuild manually with COOT (10) in a twofold averaged electron density map where after the second copy was generated by the noncrystallographic symmetry operator. A second iterative cycle consisting of model refinement with PHENIX.REFINE (11) followed by manual rebuilding was carried out until convergence. Noncrystallographic symmetry restraints were used throughout all refinement with EF-Tu divided into two bodies, EF-Ts was used as one body, and the $\beta$-subunit divided into three bodies. In the final structure, $1,192 \mathrm{C}^{\alpha}$ atoms from the one core replicase monomer superimpose onto the second core replicase with an rmsd of $0.28 \AA$, indicating very small structural differences between these. Crystallization required the presence of the nonhydrolyzable GTP analog, GDPNP, but the nucleotide could not be found in the electron density regardless of whether $5 \mathrm{mM} \mathrm{Mg}^{2+}$ was present or not during crystallization and cryoprotection. In the final cycles, the model was validated with MOLPROBITY (12) and PROCHECK (13). Ramachandran plot statistics were calculated with the latter program. Figures were prepared with PYMOL (14) or ALINE (15) and conformational changes analyzed with DYNDOM (16). The electrostatic potential was plotted on the solvent accessible surface with the APBS (17) plug-in for PYMOL. Charge and radius parameters according to an AMBER force field were assigned to the Protein Data Bank (PDB) file by the PDB2PQR Web server (18). Homology searches were conducted with DALI (19).

11. Adams PD, et al. (2002) PHENIX: Building new software for automated crystallographic structure determination. Acta Crystallogr D 58:1948-1954.

12. Lovell SC, et al. (2003) Structure validation by $C_{\alpha}$ geometry: Phi, psi and $C \beta$ deviation. Proteins 50:437-450.

13. Laskowski RA, MacArthur MW, Moss D, Thornton JM (1993) PROCHECK: A program to check the stereochemical quality of protein structures. J App/ Crystallogr 26:283-291.

14. DeLano WL (2002) The PyMOL User's Manual (DeLano Scientific, San Carlos, CA).

15. Bond CS, Schuttelkopf AW (2009) ALINE: A WYSIWYG protein sequence alignment editor for publication quality alignments. Acta Crystallogr D 65:510-512.

16. Hayward S, Berendsen HJ (1998) Systematic analysis of domain motions in proteins from conformational change: New results on citrate synthase and T4 lysozyme. Proteins 30:144-154.

17. Baker NA, Sept D, Joseph S, Holst MJ, McCammon JA (2001) Electrostatics of nanosystems: Application to microtubules and the ribosome. Proc Natl Acad Sci USA 98:10037-10041.

18. Dolinsky TJ, Nielsen JE, McCammon JA, Baker NA (2004) PDB2PQR: An automated pipeline for the setup of Poisson-Boltzmann electrostatics calculations. Nucleic Acids Res 32:W665-667.

19. Holm L, Kaariainen S, Rosenstrom P, Schenkel A (2008) Searching protein structure databases with DaliLite v.3. Bioinformatics 24:2780-2781. 

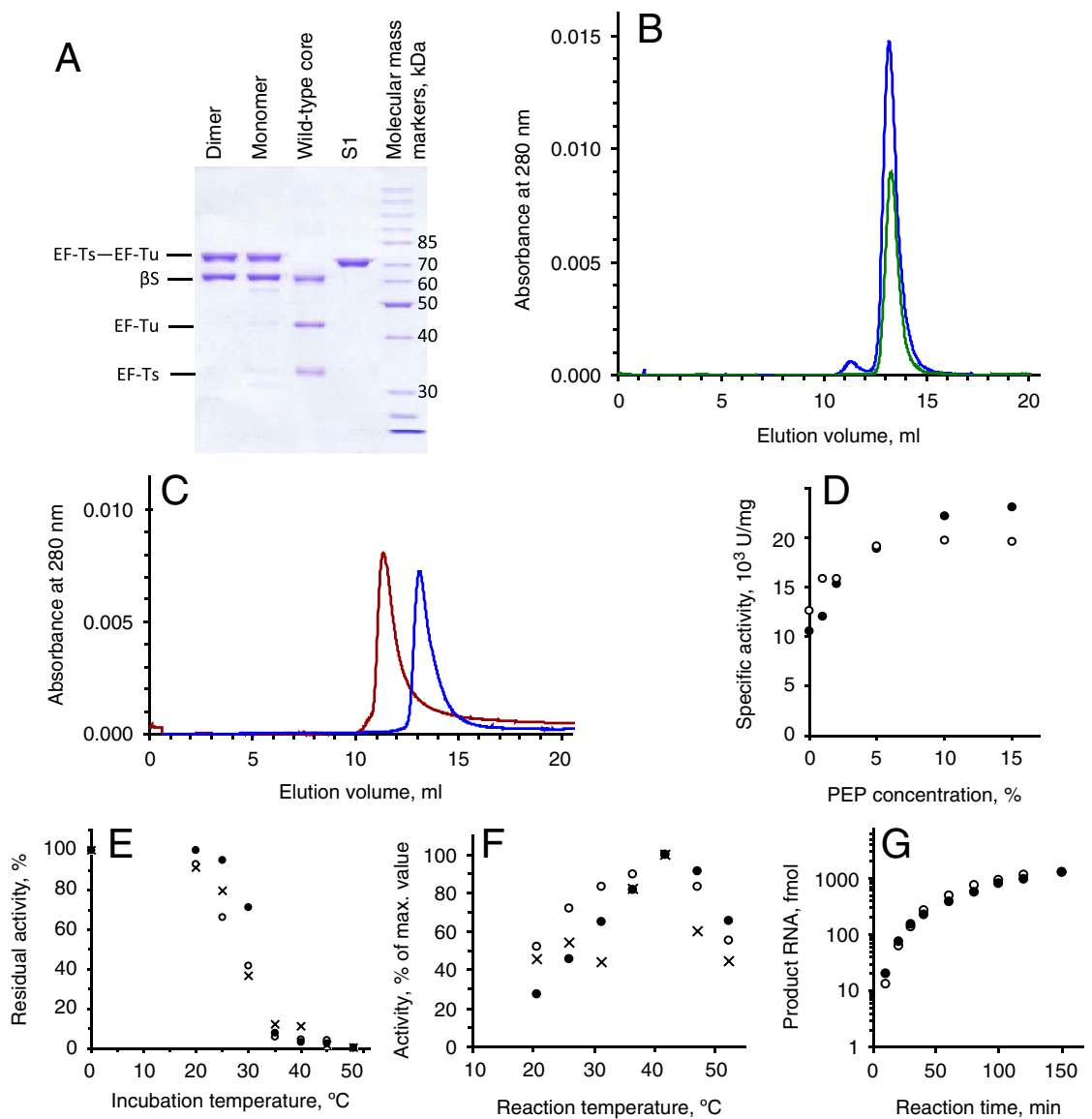

Fig. S1. Characterization of the $Q \beta$ replicase preparation used for structure determination. ( $A$ ) SDS-PAGE analysis. The gel was stained with Coomassie blue R-250. $\beta$ S denotes the $\beta$-subunit. $(B)$ Gel filtration of the isolated monomer (Blue) and of the wild-type Q $\beta$ replicase core complex (Green) in a buffer containing $500 \mathrm{mM} \mathrm{NaCl}$. The presence of a small amount of the dimer in the monomer preparation seems to be due to incomplete separation of the two forms during the isolation the monomer. (C) Gel filtration of the isolated dimer (Red) and monomer (Blue) in a buffer containing $50 \mathrm{mM} \mathrm{NaCl}$. The wide asymmetric form of the peaks seems to be due to dissociation of the $Q \beta$ replicase core into the viral $\beta$ subunit and the EF-Ts-EF-Tu fusion protein in the low salt buffer. ( $D$ ) Effects of increasing concentrations of PEP in the poly $(C)$ assay buffer on the specific activity. Open circles, filled circles, and crosses symbolize the monomer, the dimer, and the wild-type core enzyme, respectively, in this and the following panels. (E) Activity loss upon incubation in a low salt buffer during 10 min at the indicated temperatures. $(F)$ Temperature dependence of the poly $(C)$-directed activities of the monomer, dimer, and the wild-type $Q \beta$ replicase core. ( $G$ ) Time course of the amplification of $5 \mathrm{fmol}$ RQ135 RNA by $1,000 \mathrm{fmol}$ of the monomer or $500 \mathrm{fmol}$ of the dimer at $30^{\circ} \mathrm{C}$. The semilogarithmic plot allows the exponential and linear amplification phases to be distinguished. For further details, see Details of Materials and Methods. 

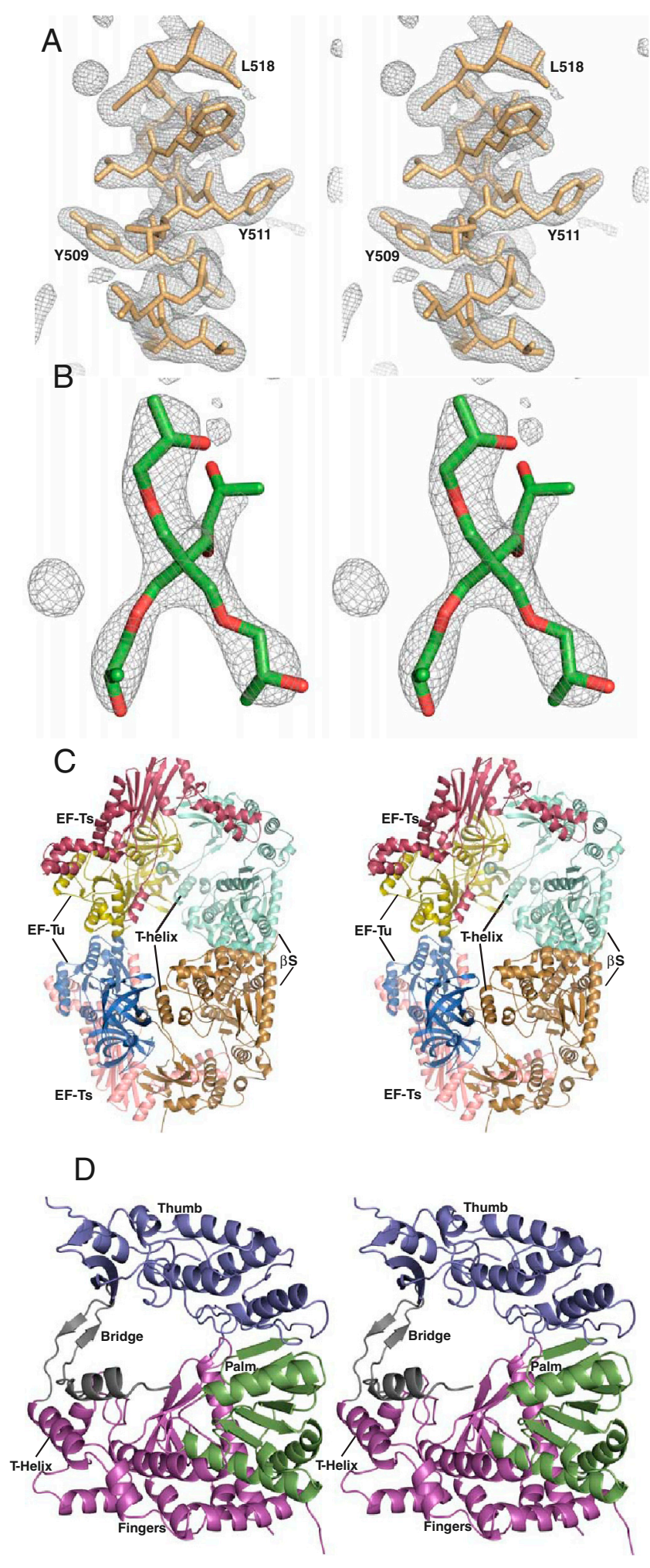

Fig. S2. Structure determination of the dimeric $\mathrm{Q} \beta$ core replicase. $(A)$ Stereo view of an omit $\mathrm{mF}_{\mathrm{o}}-\mathrm{DF}_{\mathrm{c}}$ electron density map contoured at $3.0 \sigma$ around the $\mathrm{T}$ helix of the $\beta$-subunit. $(B)$ Stereo view of an omit $\mathrm{mF}_{\mathrm{o}}-\mathrm{DF}_{\mathrm{c}}$ electron density map contoured at $3.0 \sigma$ around the PEP bound between the $\beta$-subunit and EF-Tu. (C) Stereo view of a cartoon representation of the dimeric replicase found in the asymmetric unit of the crystal. The two monomers are related by a horizontal twofold rotation axis. $(D)$ Stereo view of a cartoon representation of the $\beta$-subunit shown in the same orientation as in Fig. $2 B$. 

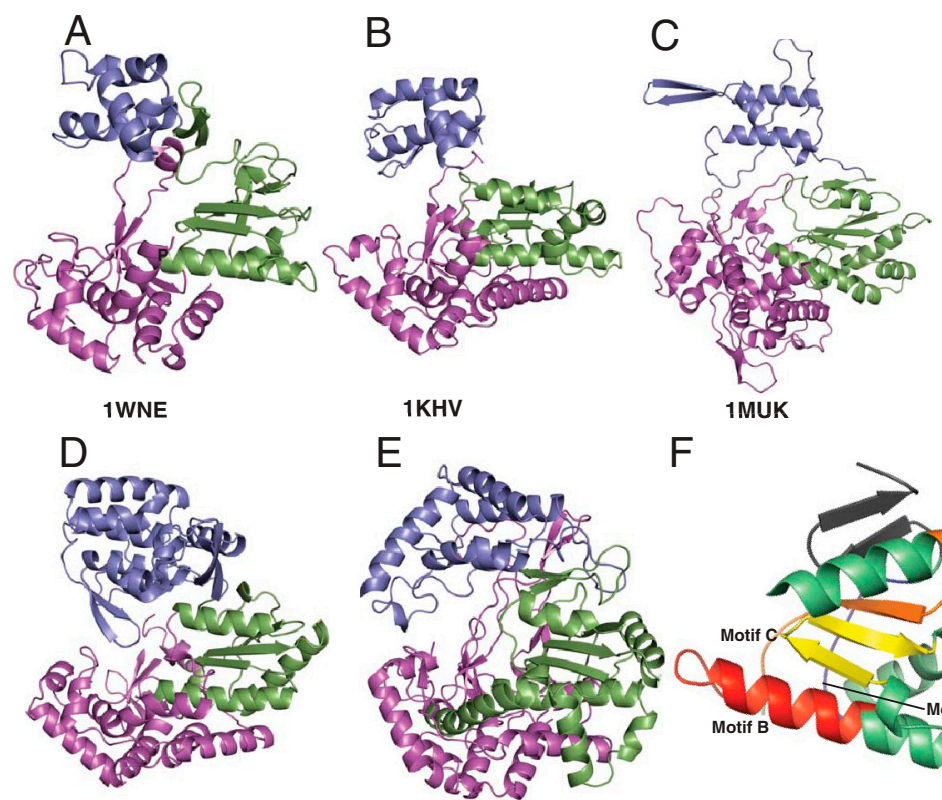

$\mathrm{E}^{1 \mathrm{KHV}}$

$\mathrm{F}$

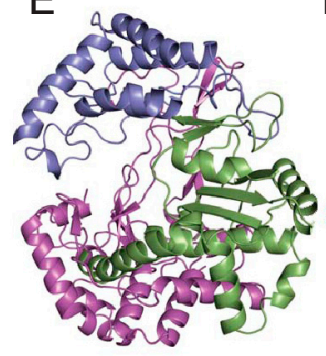

$\mathrm{F}$
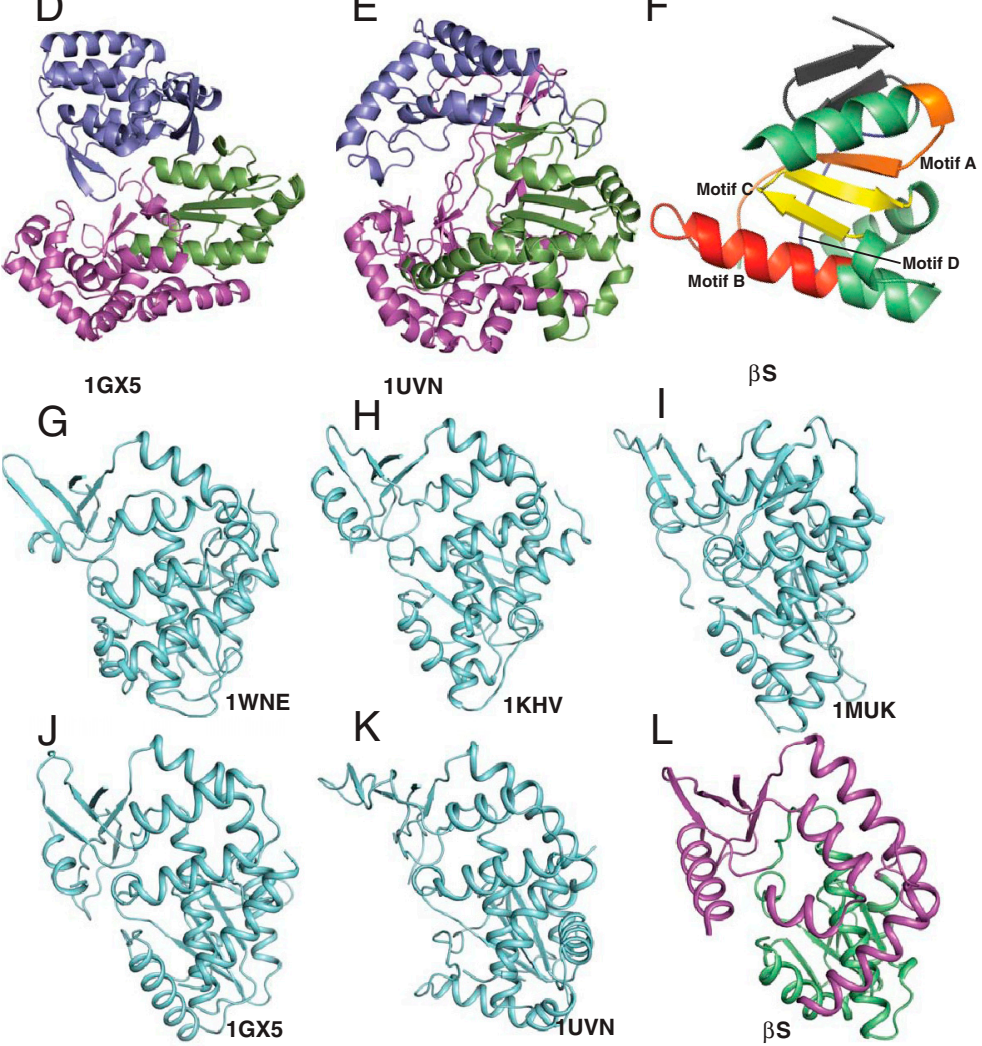

Fig. S3. Cartoon representation of five RNA-dependent RNA polymerases $(A-E)$ in the same orientation and color as in Fig. $2 B$ and of a recurring structural entity identified in all six RdRps comprised of the palm and a subdomain of the fingers domain $(G-L)$. ( $A$ and $G)$ Foot and mouth disease virus RNA-dependent RNA polymerase (PDB ID code 1WNE). ( $B$ and $H$ ) Rabbit hemorrhagic disease virus RNA-dependent RNA polymerase (PDB ID code $1 \mathrm{KHV}$ ). (C and $I$ ) Reovirus polymerase $\lambda 3$ (PDB ID code 1MUK). ( $D$ and $J$ ) Hepatitis $C$ virus RNA polymerase (PDB ID code $1 \mathrm{GX5}$ ). ( $E$ and $K$ ) RNA-dependent RNA polymerase phi6p2 (PDB ID code $1 \mathrm{UVN}$ ). (F) Cartoon representation of the palm domain of the $\beta$-subunit displaying motifs $A-D$. (L) The conserved recurring structural entity from the $\beta$-subunit colored by domains (fingers magenta and palm green). Subjection of this entity to a DALI search retrieves the Hepatitis C virus RdRp (PDB ID code $315 \mathrm{~K}$ ) with a $Z$ score of 8.7 and a rmsd of $3.4 \AA$ over 230 superimposed $C^{\alpha}$ atoms compared to 251 residues from the $\beta$-subunit in this entity. 

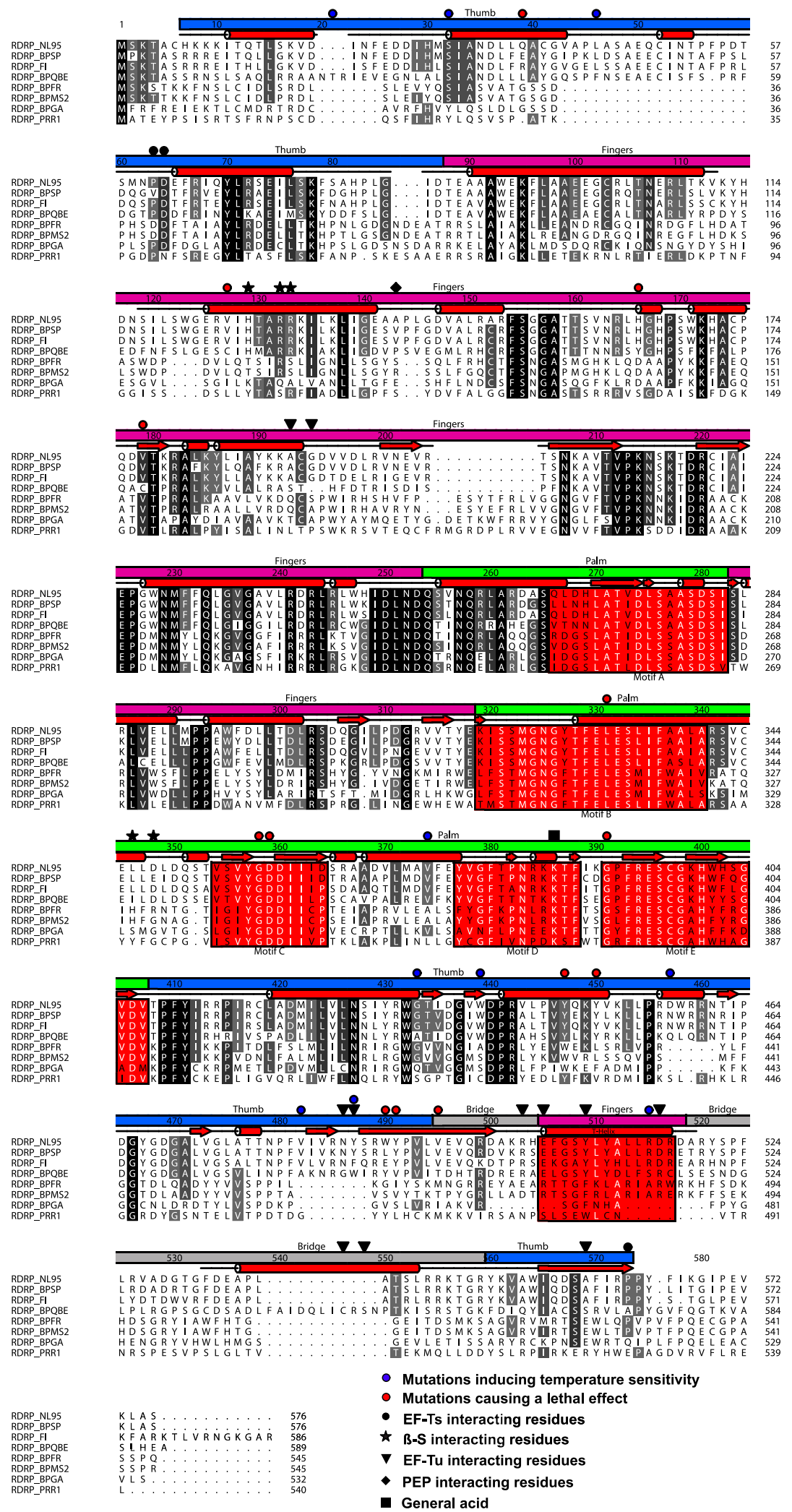

Fig. S4. Alignment of RdRp sequences from the virus family Leviviridiae. The enterobacteriophages (BP) NL95, SP, FI, and Q $\beta$ (QBE) belong to the Allolevirus genus, the enterobacteriophages FR, MS2, and GA belongs to the Levivirus genus, and PRR1 is a pseudomonas phage figuring as an unclassified Leviviridae virus. Inspection of the alignment combined with the new structural knowledge suggests that PRR1 should be classified as a Levivirus. Lethal mutations in the $\beta$-subunit (Table S2) and mutations inducing temperature sensitivity are marked with red and blue spheres, respectively. 


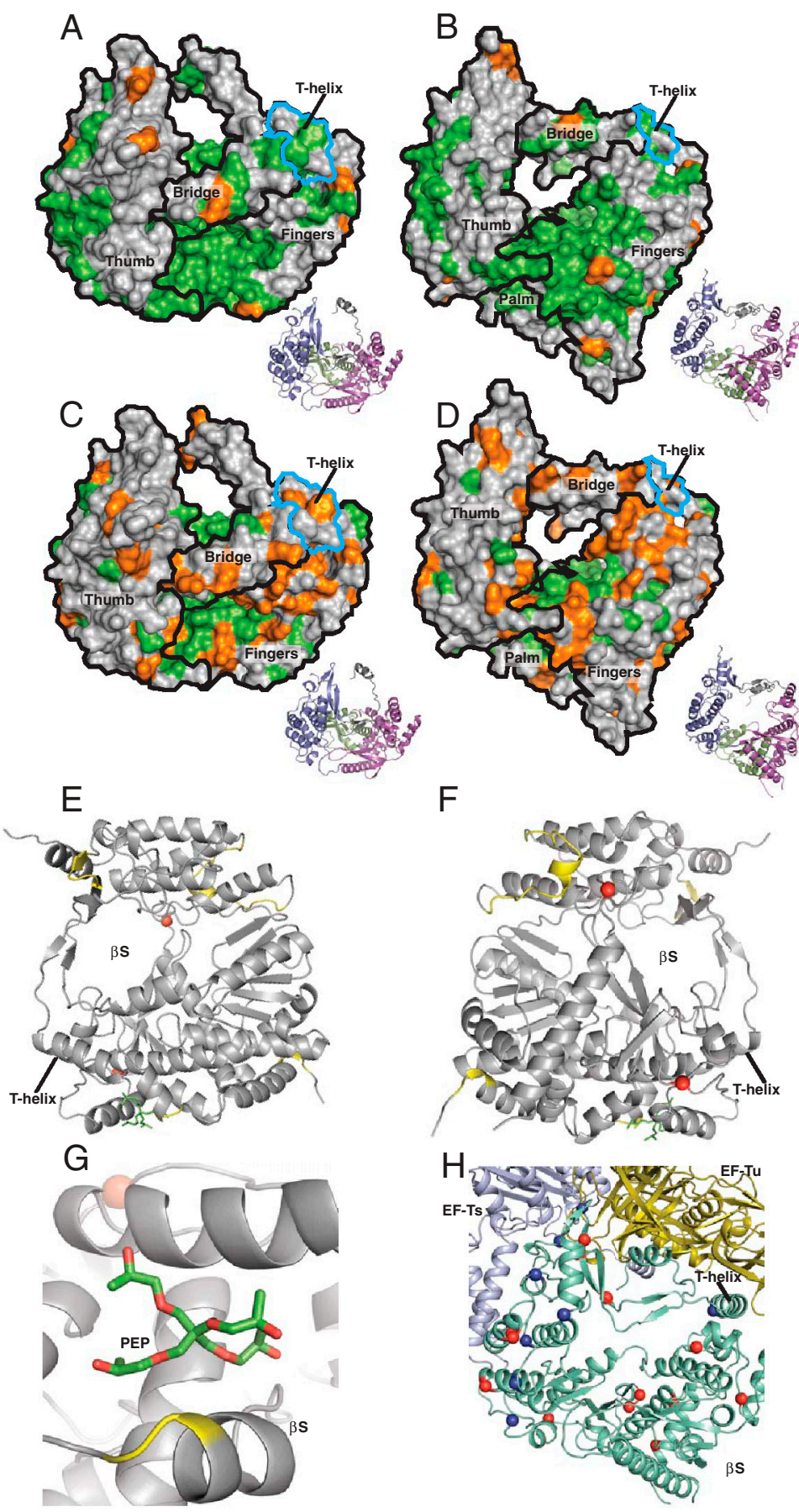

Fig. S5. Comparison of the RdRps from Allolevirus and Levivirus. ( $A$ and $B$ ) Surface representation of the $\beta$-subunit (two different orientations; $A$ has the same orientation as in Fig. 4C) colored according to conservation among Allolevirus RdRps in the sequence alignment shown in Fig. S4. Strictly conserved residues are colored green, highly conserved residues are colored orange, and nonconserved residues are colored gray. Small cartoon thumbnails with domains colored as in Fig. $2 B$ are shown for comparison. The location of the palm, fingers, and thumb domains are indicated with black outlines on the surface, whereas the $T$ helix is indicated with a blue outline. ( $C$ and $D) A s$ in $A$ and $B$, but colored after conservation among Levivirus RdRps. ( $E$ and $F$ ) Cartoon representation of the $\beta$-subunit displaying inserts (Yellow) and deletions (Red Spheres) present in Allolevivirus relative to Levivirus shown in two different orientations. (G) Close-up of the PEP binding site displaying the existence of an insert present right at the PEP binding pocket (Yellow Highlight). ( $H$ ) Cartoon representation of the Q $\beta$ replicase monomer displaying the location of the known mutations of the $\beta$-subunit as listed in Table S2. Only mutations causing a lethal effect (Red Spheres) and mutations inducing temperature sensitivity (Blue Spheres) are indicated. 

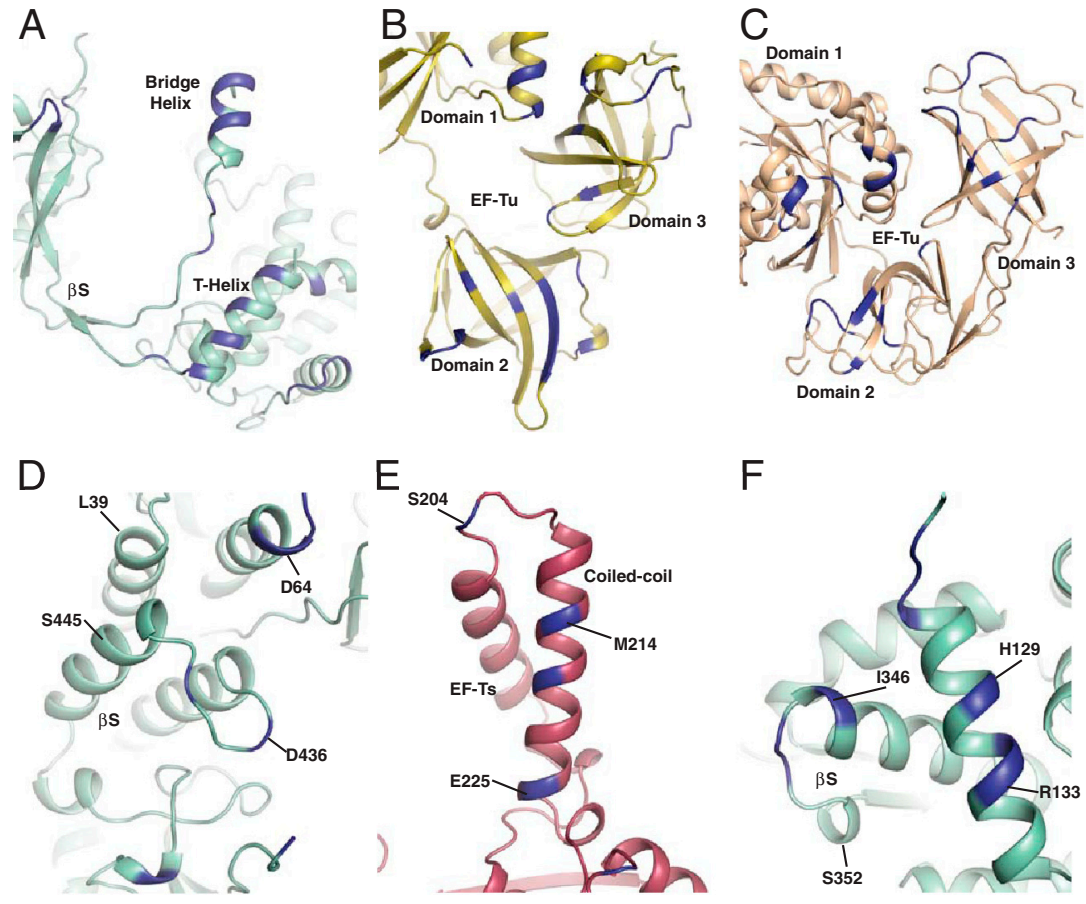

G

$\mathrm{H}$
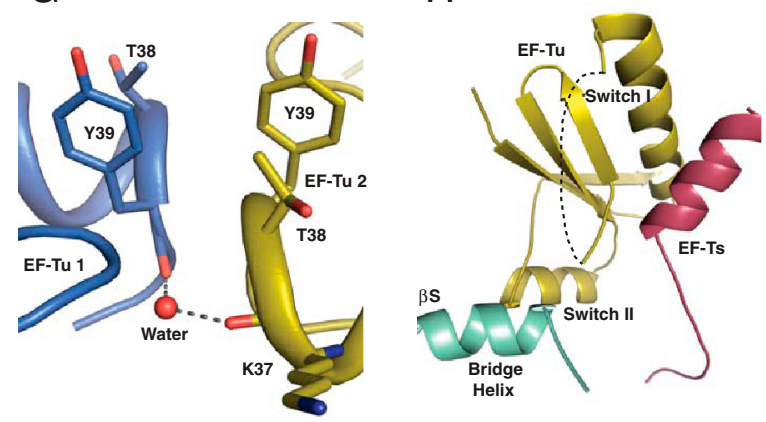

Fig. S6. Interactions between the subunits of the dimeric core replicase. (A) EF-Tu footprint onto the $\beta$-subunit. Residues in the viral subunit colored blue have atoms within $3.8 \AA$ of atoms in EF-Tu. (B) Footprint (Blue Residues) of the $\beta$-subunit onto EF-Tu. $B$ is related to $A$ by a vertical rotation of $180^{\circ}$. (C) Footprint (Blue Residues) of aa-tRNA onto EF-Tu:GTP for comparison with $B$. The orientation is changed relative to $B$ to visualize aa-tRNA interactions with EF-Tu domain 1 . (D) Footprint (Blue Residues) of EF-Ts onto the $\beta$-subunit. (E) Footprint (Blue Residues) of the $\beta$-subunit onto EF-Ts. $E$ is related to $D$ by a vertical rotation of $180^{\circ}$. $(F)$ Footprint of the $\beta$-subunit dimerization interface. Interacting surfaces are highlighted in blue. $(G)$ Detailed view of the EF-Tu:EF-Tu dimerization interface. A water molecule links the two EF-Tu molecules; otherwise, only van der Waals interactions are present at this interface. (H) Close-up of the bridge helix from the $\beta$-subunit located near the switch I (disordered, represented by a dashed line) and switch II regions of EF-Tu. 
A

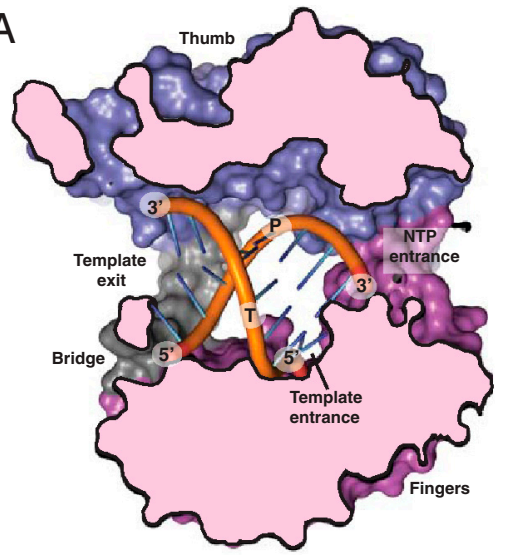

$\mathrm{B}$

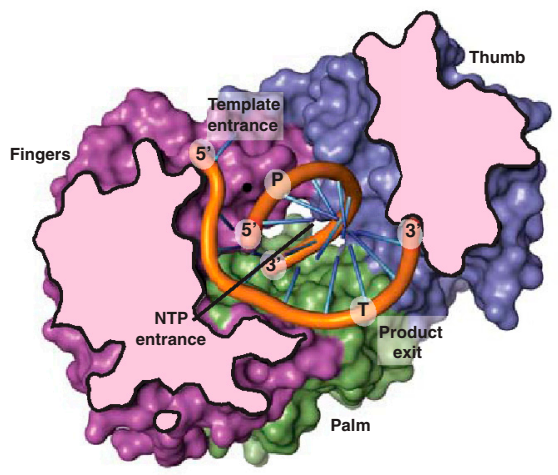

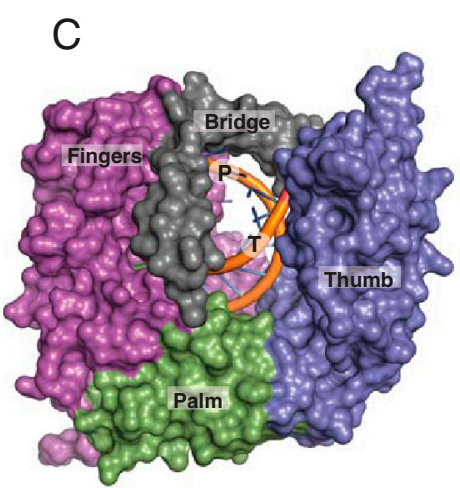

D
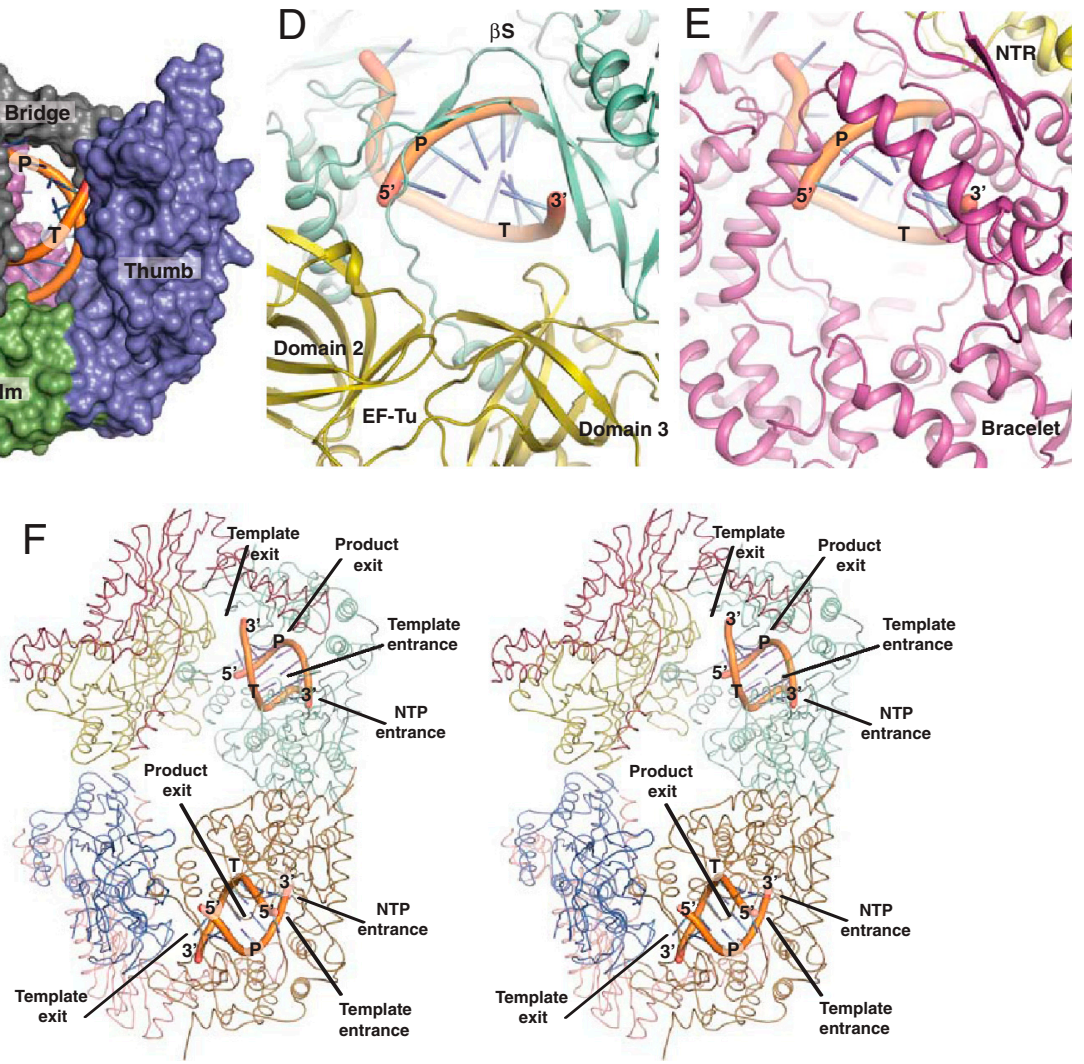

Fig. S7. The putative entrance and exit channels. The double-stranded RNA was docked by comparison with the structure of the Norwalk virus RdRp (PDB ID code 3BSN). Labels " $P$ " and " $T$ " on the RNA backbones denote product and template strand, respectively. The 3 ' and 5 ' ends of product and template are also indicated. (A) View from the palm domain displaying both the suggested entrance and exit channels for the template together with the NTP entrance channel. $(B)$ View down from the bridge region displaying both the template and NTP entrance channels and the suggested product exit channel. (C) Surface representation of the $\beta$-subunit displaying the four domains relative to the docked RNA model as seen from the outside. (D) The annular motif in the Q $\beta$ replicase is comprised of the bridge region from the $\beta$-subunit (Green) and of domain 2 and 3 from EF-Tu (Yellow). (E) The annular motif in the $\lambda 3$ RdRp (PDB ID code 1 MUK) is solely comprised of a C-terminal domain termed the bracelet. The RNA shown in both panels is from the Norwalk virus RdRp docked onto the $\beta$-subunit. The $\lambda 3 \mathrm{RdRp}$ was superimposed onto the $\beta$-subunit by matching conserved secondary structure in the palm domain. (F) Stereo view of the core replicase dimer with a docked template-product duplex showing the relationship between the entry/exit sites in the dimer. 
Table S1. Statistics for data collection and refinement

Data collection

\begin{tabular}{ll}
\hline Beam line & European Synchrotron Radiation Facility ID14-1 \\
Space group & $C 2$ \\
Unit-cell parameters & $a=245.76 \AA, b=139.47 \AA, c=101.596, \beta=92.15^{\circ}$ \\
Unique reflections & 122,562 \\
Resolution $(\AA)$ & $47.3-2.5(2.6-2.5)$ \\
Redundancy & $3.8(3.8)$ \\
Completeness $(\%)$ & $99.9(99.9)$ \\
Mean $I / \sigma$ & $18.29(2.87)$ \\
$R_{\text {sym }}(\%)$ & $11.2(57.1)$ \\
Refinement & \\
Resolution $(\AA)$ & $47.3-2.5$ \\
$R$ factor $/ R_{\text {free factor }(\%)}$ & $21.0 / 23.0$ \\
Reflections $($ work/test) & $120,569 / 1,993$ \\
Number of atoms in asymmetric unit & Protein $18446 / P E P$ 50/Water 966 \\
rmsd bonds $(\AA) / a n g l e s ~\left({ }^{\circ}\right) / B$ factor $\left(\AA^{2}\right)$ & $0.008 / 1.108 / 3.8$ \\
Ramachandran plot $(\%)$ & Most favored 92.9, additionally allowed 6.8, generously allowed 0.1, disallowed 0.2 \\
Average $B$ factor $\left(\AA^{2}\right)$ & EF-Tu:54, EF-Ts:80, $\beta$-subunit:43, water 50 \\
\hline
\end{tabular}

$R_{\text {sym }}=\left(\Sigma_{h} \Sigma_{i}\left|I(h)_{i}-\langle I(h)\rangle\right| / \Sigma_{h} \Sigma_{i} I(h)_{i}\right)$ for the intensity of reflection $h$ measured $N$ times. Values in brackets are for outer resolution shell. $R$ factor $=\left(\Sigma_{h}|| F_{\mathrm{o}}|-k| F_{\mathrm{c}}|| / \Sigma_{h}\left|F_{\mathrm{o}}\right|\right)$, where $F_{\mathrm{o}}$ and $F_{\mathrm{c}}$ are the observed and calculated structure factor, respectively, and $k$ is a scaling factor. $R_{\text {free }}$ factor is identical to the $R$ factor on a subset of test reflections not used in refinement. 
Table S2. Known effects of mutations in the $Q \beta$ replicase subunits when part of the $Q \beta$ replicase complex

\begin{tabular}{|c|c|c|c|}
\hline Subunit & Mutation & Phenotype & Reference \\
\hline \multirow[t]{24}{*}{$\begin{array}{l}\beta \text {-subunit } \\
\quad(588 \text { aa) }\end{array}$} & $\begin{array}{l}\text { C-terminal deletions up to } \\
\text { position } 571\end{array}$ & $\begin{array}{l}\text { Dispensable for replicase activity in vitro and phage } \\
\text { propagation. }\end{array}$ & (1) \\
\hline & $\begin{array}{l}\text { C-terminal deletions up to } \\
\text { positions } 565-570\end{array}$ & $\begin{array}{l}\text { Replicase activity increased in vitro, relaxed template } \\
\text { specificity. Decreased phage propagation ability. }\end{array}$ & \\
\hline & S7-grss-R8 & WT & (2); replicase activity tested in vivo \\
\hline & T21-edrss-R22 & WT at $30^{\circ} \mathrm{C}$, TS at $42^{\circ} \mathrm{C}$ & \\
\hline & L39-gkifp-A40 & D & \\
\hline & P45-ledrss-N47 & WT at $30^{\circ} \mathrm{C}$, TS at $42^{\circ} \mathrm{C}$ & \\
\hline & G61-tedlp-T62 & WT & \\
\hline & R112-grss-P113 & WT & \\
\hline & P113-edrss-Y114 & WT & \\
\hline & C127-1-stop-r-H129 & D & \\
\hline & S165-wkifh-G167 & $\mathrm{D}$ & \\
\hline & W432-gkifp-T434 & WT at $30^{\circ} \mathrm{C}$, TS at $42^{\circ} \mathrm{C}$ & \\
\hline & W439-dpdl-D440 & WT at $30^{\circ} \mathrm{C}$, TS at $42^{\circ} \mathrm{C}$ & \\
\hline & V446-wkifh-L448 & $\mathrm{D}$ & \\
\hline & Y450-grsif-R451 & $\mathrm{D}$ & \\
\hline & Q457-hrss-L458 & WT at $30^{\circ} \mathrm{C}$, TS at $42^{\circ} \mathrm{C}$ & \\
\hline & F481-gkifp-K483 & WT at $30^{\circ} \mathrm{C}$, TS at $42^{\circ} \mathrm{C}$ & \\
\hline & W487-iqiw-1488 & WT at $30^{\circ} \mathrm{C}$, TS at $42^{\circ} \mathrm{C}$ & \\
\hline & R489-wkifh-V491 & D & \\
\hline & V491-edlp-P492 & D & \\
\hline & T495-dgrss-T496 & $\mathrm{D}$ & \\
\hline & S515-grss-R516 & WT & \\
\hline & S515-grsif-R516 & WT at $30^{\circ} \mathrm{C}$, TS at $42^{\circ} \mathrm{C}$ & \\
\hline & G357A/P/M/S/V & $\begin{array}{l}\text { In vitro activities } \leq 5 \% \text { of } \mathrm{WT} \text {; rescued by } \mathrm{Mn}^{2+} \\
\mathrm{D} \text { in vivo; phage infection repressed }\end{array}$ & $(3,4)$ \\
\hline $\begin{array}{l}\text { EF-Tu } \\
\qquad(398 \text { aa) }\end{array}$ & A375T Kirromycin resistant & $\begin{array}{l}\text { 5-10\% of WT activity in poly }(C) \text { replication; rescued by } \\
\text { replacement of Mg with } \mathrm{Mn} ; 50 \% \text { of WT activity in } \\
\text { replicating QB RNA }\end{array}$ & (9) \\
\hline $\begin{array}{l}\text { EF-Ts } \\
\qquad(283 \mathrm{aa})\end{array}$ & $\begin{array}{l}\text { D184-epggea-E225 coiled-coil } \\
\text { deleted }\end{array}$ & $\begin{array}{l}\text { Mutant strain resistant towards bacteriophage QB } \\
\text { infection. }\end{array}$ & $(10)$ \\
\hline
\end{tabular}

Single amino acid codes are used to indicate the position of mutations. Insertions are indicated by lowercase letters. WT, wild-type; D, dead $(\leq 1 \%$ of WT activity); TS, temperature sensitive

1 Inokuchi Y, Kajitani M (1997) Deletion analysis of Q $\beta$ replicase. Participation of the carboxyl-terminal region of the beta-subunit protein in template recognition. $J$ Biol Chem 272:15339-15345.

2 Mills DR, Priano C, DiMauro P, Binderow BD (1989) Q $\beta$ replicase: Mapping the functional domains of an RNA-dependent RNA polymerase. J Mol Biol $205: 751-764$.

3 Inokuchi Y, Hirashima A (1987) Interference with viral infection by defective RNA replicase. J Virol 61:3946-3949.

4 Inokuchi Y, Kajitani M, Hirashima A (1994) A study on the function of the glycine residue in the YGDD motif of the RNA-dependent RNA polymerase $\beta$-subunit from RNA coliphage Q $\beta$. J Biochem 116:1275-1280.

5 Knudsen CR, Clark BF (1995) Site-directed mutagenesis of Arg58 and Asp86 of elongation factor Tu from E. coli: effects on the GTPase reaction and aminoacyl-tRNA binding. Prot Eng 8:1267-1273.

6 Mathu SGJ, Knudsen CR, van Duin J, Kraal B (2003) Isolation of Q $\beta$ polymerase complexes containing mutant species of elongation factor Tu. J Chromatogr B 786:279-286.

7 Pedersen GN, Rattenborg T, Knudsen CR, Clark BFC (1988) The role of Glu259 in Escherichia coli elongation factor Tu in ternary complex formation. Prot Eng 11:101-108.

8 Rattenborg T, Pedersen GN, Clark BFC, Knudsen CR (1997) Contribution of Arg288 of Escherichia coli elongation factor Tu to translation functionality. Eur J Biochem 249:408-414.

9 Blumenthal T, Saari B, Van der Meide PH, Bosch L (1980) Q $\beta$ replicase containing wild type and mutant tufA and tufB gene products. J Biol Chem 255:5300-5305.

10 Karring H, et al. (2004) Q $\beta$-phage resistance by deletion of the coiled-coil motif in elongation factor Ts. J Biol Chem 279:1878-1884. 
Table S3. Comparison of molecular interfaces calculated by PISA (1) Interface

\begin{tabular}{lrrr}
\hline$\beta$-subunit: $\beta$-subunit & 1,770 & -9.0 & 0.305 \\
$\beta$-subunit:EF-Tu & 3,766 & -22.9 & 0.040 \\
$\beta$-subunit:EF-Ts & 1,522 & -12.1 & 0.109 \\
EF-Tu:EF-Tu & 556 & -0.7 & 0.386 \\
\hline
\end{tabular}

*Solvation free energy gain upon formation of the interface. This does not include salt bridges and hydrogen bonds.

${ }^{\dagger}$ Probability of getting a lower than obtained $\Delta^{\mathrm{i}} \mathrm{G}$, if interface atoms are picked randomly from protein surface such as to amount to the observed interface area. $P$ value is a measure of interface specificity, showing how surprising, in energy terms, the interface is. A value of $P=0.5$ indicates an average hydrophobicity of the interface, at $P>0.5$ the interface is less hydrophobic than could be expected, and at $P<0.5$ the interface is more hydrophobic than could be expected.

1 Krissinel E, Henrick K (2007) Inference of macromolecular assemblies from crystalline state. J Mol Biol 372:774-797. 